NBER WORKING PAPER SERIES

\title{
DO INDIVIDUALS MAKE SENSIBLE HEALTH INSURANCE DECISIONS? EVIDENCE FROM A MENU WITH DOMINATED OPTIONS
}

\author{
Saurabh Bhargava \\ George Loewenstein \\ Justin Sydnor \\ Working Paper 21160 \\ http://www.nber.org/papers/w21160
NATIONAL BUREAU OF ECONOMIC RESEARCH
1050 Massachusetts Avenue
Cambridge, MA 02138
May 2015

We thank a number of individuals for their generous advice and feedback including Alan Auerbach, Ned Augenblick, Linda Babcock, Zarek Brot-Goldberg, Ryan Bubb, David Card,David Coughlin, Stefano DellaVigna, Joe Farrell, Ben Handel, Hilary Hoynes, Botond Koszegi, Prasad Krishnamurthy, David Laibson, Bridget Madrian, Ulrike Malmendier, Daniel McFadden, John Miller, Sendhil Mullainathan, Devin Pope, Matthew Rabin, Emmanuel Saez, Joshua Schwartzstein, Andrei Shleifer, and David Sraer. We additionally thank seminar participants at U.C. Berkeley, Carnegie Mellon University, Case Western University, Cornell University, Georgia State, Harvard Business School, Harvard University, the London School of Economics, M.I.T., and Oxford University. The views expressed herein are those of the authors and do not necessarily reflect the views of the National Bureau of Economic Research.

NBER working papers are circulated for discussion and comment purposes. They have not been peerreviewed or been subject to the review by the NBER Board of Directors that accompanies official NBER publications.

(C) 2015 by Saurabh Bhargava, George Loewenstein, and Justin Sydnor. All rights reserved. Short sections of text, not to exceed two paragraphs, may be quoted without explicit permission provided that full credit, including $\odot$ notice, is given to the source. 
Do Individuals Make Sensible Health Insurance Decisions? Evidence from a Menu with Dominated Options

Saurabh Bhargava, George Loewenstein, and Justin Sydnor

NBER Working Paper No. 21160

May 2015

JEL No. D82,D89,I11,I13

\begin{abstract}
The recent expansion of health-plan choice has been touted as increasing competition and enabling people to choose plans that fit their needs. This study provides new evidence challenging these proposed benefits of expanded health-insurance choice. We examine health-insurance decisions of employees at a large U.S. firm where a new plan menu included a large share of financially dominated options. This menu offers a unique litmus test for evaluating choice quality since standard risk preferences and beliefs about one's health cannot rationalize enrollment into the dominated plans. We find that a majority of employees - and in particular, older workers, women, and low earners - chose dominated options, resulting in substantial excess spending. Most employees would have fared better had they instead been enrolled in the single actuarially-best plan. In follow-up hypothetical-choice experiments, we observe similar choices despite far simpler menus. We find these choices reflect a severe deficit in health insurance literacy and naïve considerations of health risk and price, rather than a sensible comparison of plan value. Our results challenge the standard practice of inferring risk attitudes and assessing welfare from insurance choices, and raise doubts whether recent health reforms will deliver their promised benefits.
\end{abstract}

Saurabh Bhargava

Carnegie Mellon University

sbhar@andrew.cmu.edu

George Loewenstein

Carnegie Mellon University

g120@andrew.cmu.edu
Justin Sydnor

Wisconsin School of Business

ASRMI Department

University of Wisconsin at Madison

975 University Avenue, Room 5287

Madison, WI 53726

and NBER

jsydnor@bus.wisc.edu 
Across the many financial decisions facing Americans, those involving health insurance are among the most economically consequential and poorly understood. A majority of insured Americans worry that unexpected health expenses pose a threat to a secure retirement and financial well-being, but only $14 \%$ of the insured are able to define the basic cost-sharing concepts fundamental to most health insurance plans (Loewenstein et al. 2013). ${ }^{1}$ This lack of health-insurance literacy mattered less when most individuals simply accepted the single-plan offered by their employer, Medicare, or Medicaid, but in recent years there has been a trend towards providing individuals with greater choice. Seniors select from numerous and highly differentiated plan options when enrolling in Medicare Part D or Medicare Advantage, and the median enrollee on the exchanges of the Affordable Care Act (ACA) chooses from 47 available plans. In theory, choice should improve consumer welfare both by enhancing the ability of individuals to sort into suitable plans and by encouraging provider competition. As Kathleen Sebelius, former Secretary of Health and Human Services, stated during the rollout of the ACA exchanges, "Exchanges offer Americans competition, choice, and clout. Insurance companies will compete for business on a transparent, level playing field, driving down costs, and Exchanges will give individuals... a choice of plans to fit their needs."

However, recent research has challenged the economic rationale for expanding health-plan choice by questioning whether consumers can sensibly navigate the choices they face. A series of influential studies established that seniors make poor decisions about drug coverage on the highly complex Medicare Part D exchanges. Abaluck and Gruber (2011) conclude that a majority of enrollees could have selected alternative plans with both lower premiums and lower variance in cost suggesting widespread inefficiency in choice. $^{2}$ Kling et al (2012) find that providing seniors with simple information on the expected spending associated with different plans led to substantial plan switching, implying that seniors had not previously compared the financial value of different plans. Seniors do reduce excess spending over time (Ketcham, et al. 2012), but appear to exhibit considerable inertia when it comes to changing plans (Ericson, forthcoming). Outside the complicated domain of Medicare, most evidence on the quality of plan choice has been limited to the problem of consumer inertia. Inertia in plan choice has been documented in employee populations (Strombom et al. 2002; Frank and Lamiraud, 2009), and Handel (2013) reports cases in which this inertia leaves employees with substantially dominated plans. Assessing the quality of active employee choices from straightforward plan menus has been more challenging since

\footnotetext{
${ }^{1}$ Survey involved 1,847 insured US adults and was retrieved November 2014 from http:/ / newsroom.cigna.com/ images/9022/media_gallery/knowyourbenefits/2014_Health_Financial_Well-Being-How_Strong_Is_The_Link-FINAL.pdf.

2 See also Heiss, McFadden and Winter (2010) and Zhou and Zhang (2012) for similar evidence in this market.
} 
these choices reflect factors such as a tolerance for risk and expectations regarding future medical care that are not readily observed by researchers.

In this paper, we present new evidence on the quality of insurance plan choices made by over 50,000 employees of a large US firm. Employees in our sample were required to assemble their own health plan by selecting options for four cost-sharing dimensions (deductible, out-of-pocket maximum, copay and coinsurance). The resulting "build-your-own" menu featured 48 plans which varied in costsharing and premium but were otherwise equivalent.

The decisions faced by these employees provide a unique litmus test for assessing the quality of health plan choices, due to two key features. The first key feature is that the majority of the plan options were financially dominated by other available plans. That is, employees chose from a menu in which some plans were less costly regardless of the employee's ultimate level of medical care. A menu with a significant share of financially dominated options can reveal choice quality without assumptions about consumer beliefs or risk preferences. As an illustration of plan dominance, employees shopping for single-person coverage who had the choice of four deductibles $(\$ 1000 ; \$ 750 ; \$ 500 ; \$ 250)$ typically had to pay more than $\$ 500$ to reduce their deductible from $\$ 1,000$ to $\$ 750$, holding all other plan features equivalent. This price difference cannot be rationalized by any level of health-care utilization since the employee could save at most $\$ 250$ with the lower deductible. ${ }^{3}$ Of the 36 low-deductible plans available, 35 were dominated in this way. The second key feature is the fact that the plans, apart from varying across the four cost-sharing dimensions and premium, were otherwise identical and were presented in a highly standardized manner. The plans were provided by the same health insurance company (eliminating possible differences in provider reputation) and featured the same coverage in- and out-of- network. As a result of these two features, the apparent dominance of plans should not have been confounded by actual, or perceived, differences in other plan attributes, and the identification of such dominance should not have required extraordinary consumer sophistication.

Our main empirical result is that the majority of employees chose plans that were financially dominated. ${ }^{4}$ The economic consequences of these poor choices for those who made them were significant. The average employee opting into a dominated plan could have saved $\$ 373$ per year by choosing an otherwise equivalent plan with a higher deductible, which is equivalent to $2 \%$ of mean annual income and $42 \%$ of the average employee-paid premium. Choice quality varies by employee

\footnotetext{
${ }^{3}$ While we focus on employees choosing single coverage plans, we find that choices of other employees are similar. ${ }_{4}^{4} 61 \%$ chose a transparently dominated plan before tax considerations, while $55 \%$ chose a dominated plan adjusting for the differential tax deductibility of premiums over out-of-pocket spending.
} 
characteristics: Lower-income employees, female employees, older employees, and employees with chronic health conditions were all significantly more likely to select dominated contracts. Indicative of the welfare consequences of these choices, employees in the lowest band of reported income could have saved over $4 \%$ of annual income, on average, with the actuarially best plan. This evidence suggests that the burden of complex insurance decisions may disproportionately affect the most financially vulnerable. We also find, consistent with prior studies documenting consumer inertia, that only a modest share of employees switched into new plans the subsequent year. While the plurality of these switchers moved to financially superior plans, switching rates were lower for low-income employees.

Given the financial consequences of plan choice, why do so many employees choose dominated plans? One possibility is that sophisticated employees knowingly pay a premium for the ease and predictability of incurring steady payroll deductions as compared to a more variable flow of out-of-pocket expenses. However, for the $36 \%$ of employees choosing the mid-level $\$ 500$ deductible, such preferences imply paying an additional $\$ 625$ in premiums to avoid an expected marginal increase of $\$ 230$ in out-ofpocket expenses, and a maximum of $\$ 500$ in such expenses, over the course of the year. While we cannot definitely rule out this explanation, given the availability of alternative sources of financing available to most employees (e.g., flexible savings accounts) and the fact that dominated plans would generally change the flow of out-of-pocket costs only for a narrow range of total medical expenses, it is unlikely that consumer preference for improving the predictability of expenses accounts for a large share of the observed behavior. Similarly, while sophisticated employees might choose dominated options to avoid underusing valuable health-care in the face of cost-sharing, as suggested by recent theory (Baicker, Mullainathan and Schwartsztein 2013), such costly commitments are of limited benefit in a setting like ours in which such "behavioral moral hazard" could change marginal incentives for only a narrow range of observed outcomes. ${ }^{5}$

Assuming, then, that the observed choices of dominated contracts represent a financial mistake, we investigate explanations through a series of online experiments. These experiments involved thousands of subjects who were asked to make plan choices from stylized menus that were designed to mimic the firm's menu in price and structure, but were dramatically simplified. Speaking to the reliability of the experiments, subjects across a range of conditions produced the same double-peaked pattern in deductible choice, with peaks in demand for the $\$ 500$ and $\$ 1,000$ deductibles, as that exhibited by the firm employees. We initially test whether employee choice was due to the search complexity associated with

\footnotetext{
5 The marginal incentives for using health care differ across plans primarily for the small range of outcomes where the total yearly medical bills fall between two deductibles (e.g., between $\$ 500$ and $\$ 1,000$ ).
} 
the large number of available plan options and the particular design of the enrollment interface faced by employees. $^{6}$ Our experimental test of search complexity, in which we varied the number of plans and plan attributes available, the ease with which subjects could compare plans, and the consistency with which plan premiums and deductibles were presented, suggests that reducing such complexity improves choice, but only modestly. A majority of subjects failed to detect dominated plans even when presented with an extremely simple menu featuring four plans differing only on deductible and price.

Given the modest role of search complexity in explaining choice quality, and in light of prior research on the pervasiveness of health illiteracy, in a second online experiment we explored the possibility that poor choice was a consequence of either a deficit in search motivation or low levels of health insurance literacy. While we found that a majority of subjects do not anticipate that plan menus might include plans of low financial value, our attempts to inform people of the financial implications of choice led to very little choice improvement. Consistent with this latter result, most subjects lacked definitional and conceptual understanding of insurance concepts such as a deductible and copayment, and these deficits in insurance literacy predicted poor plan choices. Further implicating the importance of literacy in explaining poor choice, the introduction of real-time decision-aids designed to educate subjects led to significant improvements in choice quality.

While the choice inefficiency exhibited by employees and experimental subjects appears largely attributable to consumer illiteracy with respect to the basic structure of insurance, the deductible choices we observe are far from random. In particular, we document evidence for adverse selection in that older and sicker employees are more likely to select into plans with more insurance coverage. In a final experiment, we explore how beliefs about health risk predict demand for coverage. We again present subjects with simple menus and dominated options, but systematically vary the relative cost of plans and elicit perceptions of risk and health. We find that while consumer choice is modestly sensitive to changes in the relative cost of price sharing across menus - a demand elasticity which resembles consumers choosing insurance from non-dominated plans (Einav, Finkelstein and Cullen 2010) — it is strongly predicted by perceived health status. Less healthy subjects are far more likely to choose additional coverage even when the cost of that additional coverage is so high as to result in dominated options. Overall, the choices appear consistent with a heuristic choice strategy in which individuals sort themselves into plans based on an inference about varying plan generosity and perceptions of their own relative

\footnotetext{
${ }^{6}$ The online interface through which employees enrolled in a plan was designed to emphasize the sense that employees could "build" their own health plan by sequentially selecting levels within each of four cost-sharing attributes after which plan features and the monthly cost was displayed. After building a first candidate plan, employees had the option of enrolling in that plan or building subsequent plans which would be iteratively added to a plan comparison matrix.
} 
healthiness, but without a full financial comparison of plan values (a la Prelec, Wernerfelt \& Zettelmeyer 1997, Kamenica, 2008). The possibility that individuals rely on imperfect heuristics to navigate consequential decisions is consistent with broader research showing that individuals, faced with complex choices, make systematic, and costly, mistakes, due to limits to cognition, motivation, and self-control (see DellaVigna 2009).

The poor health plan choices we document have implications for policy. A first implication is that the pervasiveness, and persistence, of poor plan choices undermines the stated rationale for choice expansion. If employees are not able to sensibly compare across plans in a standardized menu in which all plans have the same insurance provider and vary on only a few features, then it is unlikely that consumers faced with the far more heterogeneous menus in public exchanges will make much better choices. Rather than improving plan selection, our findings suggest that the availability of choice may have led to an increase in spending and loss of consumer welfare that outweighs other consequences of healthcare reform - e.g., the downward effect on premiums of competition in healthcare exchanges (e.g., Burke et al. 2014), or the effect of the mandate on plan prices (e.g., Eibner and Price 2012) — that have attracted considerable policy attention. Beyond the effects of choice on individual well-being, the inability of consumers to financially compare plans may cause providers to leverage product complexity to extract additional economic rents (Sandroni and Squintani 2007; Ho, Hogan, and Morton 2014; Gabaix and Laibson 2006; DellaVigna and Malmendier 2004; Heidhues and Koszegi 2014).

The widespread lack of health plan literacy also speaks to the potential benefits of facilitating consumer decisions with simplification and appropriately tailored decision-aids. Among both employees and our experimental subjects, those with low literacy or low self-reported income made inferior plan choices. In the experiments, simplification and, to a far greater extent, education, improved choice quality, especially among employees with lower incomes. Yet, the persistence of a non-trivial share of poor choice across our studies - even with aggressive treatments, nearly $30 \%$ of subjects continued to select dominated options-implies a ceiling in the efficacy of even the most benevolent of choice environments. These results lend support to recent arguments that policies requiring providers to restrict choice sets to plans that are suitable for a particular consumer, or to simplify and standardize the structure of insurance products may be more effective at improving consumer welfare and ensuring competitive prices than policies aimed at simplifying choice environments. (Loewenstein and Volpp 2011; Bhargava and Loewenstein 2015).

Finally, the results of this study have broader implications for evaluating risk and welfare from consumer choices in insurance markets (see Einav, Finkelstein and Levin, 2010 for a review). The 
approach in this literature builds on the canonical model of insurance choice (Rothschild and Stiglitz, 1976), in which the demand for insurance comes from the value of reducing variance in spending for risk-averse consumers with private information about their health risk. However, as Handel and Kolstad (forthcoming) discuss, if consumer demand for insurance reflects informational frictions or decisionmaking bias, inferences regarding risk attitudes and welfare dynamics made from such choices may be misleading. ${ }^{7}$ Our results, in which a majority of employees and online subjects select dominated contracts, complement this work by documenting clear violations of the standard model of insurance choice. Since our setting involves poor choices across options that vary only on price and cost-sharing dimensions, our findings motivate the need for new approaches for describing insurance demand which reflect an even more fundamental departure in how people evaluate health plans than those adopted by prior work.

While individuals may not commonly face dominated health plan options of the sort examined here, the economics and welfare implications underlying the behavior we observe may be far more widespread. We illustrate the broader applicability of our findings using the framework developed by Einav, Finkelstein and Cullen (2010). First, we show how, in the face of substantial adverse selection, high prices for modest reductions in cost sharing for health plans (including dominated pricing) can emerge. ${ }^{8}$ In such situations, high-risk individuals who lack insurance sophistication may select into high coverage plans that reveal one's risk type while offering only benefits through additional insurance (Baker 2011). Next, we highlight simple indicators in this framework that help identify when choices deviate meaningfully from the standard model even in situations without strictly dominated contracts. The health-plan choices by employees in the Einav, Finkelstein and Cullen (2010) study, for example, exhibit these indicators of non-standard preferences even though that setting does not involve dominated options. Finally, through a simulation of plan choices, we show that failing to account for a heuristic choice process, consistent with the behavior we document, can lead to a substantial mis-estimation of the welfare loss associated with adverse selection.

Our work builds on several interconnected literatures. Our primary analysis of plan choice and inertia follows up on studies documenting sub-optimal health plan decisions and inertia among seniors. Unlike the complex environment of Medicare Part D, which features a wide variation in plan price, coverage, and design, and requires consumers to make complicated multi-attribute comparisons, we

\footnotetext{
${ }^{7}$ See also Anatasov and Baker (2014) who provide some similar evidence about biased beliefs about health plans.

8 This happens if plan prices are based on the total average cost differences between groups selecting different plans rather than on the average cost of the additional coverage provided to those opting for lower cost sharing plans.
} 
investigate choice in highly standardized setting. The experiments we use to explore decision-making mechanisms, and to identify possible strategies to improve choice, parallel other studies in which subjects are asked to make choices from hypothetical plan menus Johnson et al. 2013; Schram and Sonnemans, 2011; Bhargava, Loewenstein and Benartzi 2015). In documenting the pervasiveness and consequences of low health plan literacy, we contribute to a growing literature which points to the likelihood that individuals misconstrue important health incentives (e.g., Loewenstein et al. 2013; Winter et al., 2006; Handel and Kolstad 2013). Our findings regarding the large, and potentially regressive, costs of complexity are in line with other demonstrations of how complexity adversely affects behavior across a range of economically important settings. ' Finally, our work contributes to the rapidly emerging literature on behavioral considerations in insurance markets, and highlights the importance of continued research on the role of cognitive limitations and search frictions (Fang, Keane and Silverman, 2008; Handel and Kolstad, forthcoming; Spinnewijn, 2014, Schmitz and Ziebarth, 2015), non-standard risk preferences (Koszegi and Rabin, 2007; Sydnor, 2010; Bordalo et al., 2012; Barseghyan et al., 2013, 2014) and decision heuristics (Ericson and Starc, 2012).

\section{SECTION 2. DATA AND INSTITUTIONAL BACKGROUND}

In our main analysis, we draw on administrative data on medical claims and plan choice for 2010 and 2011 from a Fortune 100 firm whose identity we suppress for confidentiality. This section summarizes relevant institutional detail, the data, and descriptive statistics. We separately describe the data and subject characteristics for the mechanism experiments in Section 4.

\subsection{Background and Institutional Detail}

Structure of Health Plan Menu. In 2010 the firm replaced its existing menu of three plans and a highly varied bundle of plan attributes (Basic, Plus, Premium), with a "Build Your Own" regime in which employees were offered a choice from a standardized menu of 48 plans. For employees choosing single coverage, the focus of our analysis, these plans represented the full conjoint of available options across 4 annual deductibles $(\$ 1000 ; \$ 750 ; \$ 500 ; \$ 350), 3$ levels of maximum-out-of-pocket spending above the deductible ( $\$ 3000 ; \$ 2500 ; \$ 1500 ;$ MOOP), 2 coinsurance rates on coverage above the deductible and before the out-of-pocket $\max$ is hit (80\%; 90\%), and 2 office copayments ( $\$ 15$ for Primary Care Visits /

\footnotetext{
${ }^{9}$ For example, school choice (Hastings and Weinstein 2008), retirement savings (e.g., Choi et al. 2009), and take-up of social benefit programs (Bhargava and Manoli 2014).
} 
\$40 for Specialist Visits; \$25 for Primary Care Visits / \$35 for Specialists). Out-of-network, all plans featured a $\$ 3,500$ deductible a $\$ 7500$ out-of-pocket maximum and either a $50 \%$ or $60 \%$ coinsurance rate depending on the choice of in-network coinsurance. Beyond the described variation in cost-sharing, plans were otherwise identical. In the following year, the set of available plans did not change with respect to their cost-sharing features. Table 1 reports details for the plan menu. ${ }^{10}$

Plan Pricing and Dominated Choices. Our ability to characterize choice quality rests on the price domination reflected in plan menus and a high degree of plan standardization which facilitates easy comparisons across plans. For example, Plan 13 is identical to Plan 37, except in the deductible level which varies by $\$ 500$. Plan 13 (with the $\$ 500$ deductible) costs $\$ 638$ more in annual premium than Plan 37 (the $\$ 1,000$ deductible). Because the difference in plan premiums exceeds the difference in deductibles, Plan 13 is financially dominated by the otherwise equivalent plan with the $\$ 1,000$ deductible. Of the 36 low-deductible plans, 35 are financially dominated as indicated by the highlighted sections of Table 1, with the premium of Plan 24 falling $\$ 20$ short of a fully dominated plan menu by deductible.

Figure 1 presents an alternative way of visualizing the dominance of plan menus. This figure shows the schedule of medical spending (i.e., employee premium plus out-of-pocket costs) an employee would be responsible for as a function of total medical expenses/bills for plans with a maximum out of pocket of $\$ 2,500,80 \%$ coinsurance and the $\$ 25 / \$ 35$ copay level. Of employees choosing single coverage, 15.5 percent chose a plan from this set which contains the second most popular plan option overall (i.e., the $\$ 500$ deductible). The figure depicts schedules for the four different deductible levels available and normalizes the premium of the $\$ 1,000$-deductible plan at $\$ 0$. One plan is dominated by another if that plan's cost schedule is above the other for the entire range of medical spending. Among plans in this representative set, each plan with a lower deductible is dominated by the plan with the $\$ 1,000$ deductible while the $\$ 350$ deductible plan is dominated by all of the other deductible levels.

Given that health-insurance premiums are generally tax deductible, while out-of-pocket expenses are not, plans that appear to be dominated on a nominal basis may not be strictly dominated after adjusting for an employee's marginal tax rate. Table 1, which also depicts plan dominance using the average marginal federal income tax rate (implied by salary bands available in the data) across employees of $19 \%$ to adjust for premium deductibility, shows little erosion in the share of dominated plans due to

\footnotetext{
10 Plan prices feature small differences across geographic area and business units. Prices are averaged across geographies and business units (but not coverage tier) for our analysis. According to the Firm, such price differences are modest, and do not meaningfully affect price differences across plans for a given geography area $\mathrm{x}$ business unit.
} 
tax adjustments in that 30 plans remain dominated. When feasible, we report our analysis of plan choice after adjusting for taxes using estimates of employee-specific marginal federal income tax rates.

Our analysis includes a description of plan switching by employees in 2011 . While the plan menu faced by employees in 2011 was identical with respect to the structure of plans, plan prices grew by an average of $31 \%$ across plans and this increase was fairly consistent across plans by level of cost-sharing. The consistency in this price increase actually led to an increased degree of price domination in 2011 such that, without tax adjustment, all 36 low deductible plans were financially dominated.

Plan Enrollment. During the open enrollment period in May 2010, eligible employees, excluding new hires, were asked to enroll in a medical plan for "Plan Year" 2010 extending from June 1", 2010 through May 31 $1^{\text {st }}, 2011{ }^{11}$ For simplicity, we refer below to plan years by the year in which the selection was made (e.g., 2010 refers to PY 2010). Eligible new hires were permitted to choose a plan outside the enrollment period, after a three month waiting period, unless the hiring date was proximal to the enrollment period. Given that plan options changed in 2010, employees were encouraged to make an active choice into a new health plan. If an employee with existing coverage did not actively elect a new plan, he or she was defaulted into Plan 48, which had minimum premium and the maximum possible cost-sharing on each dimension and, importantly, was not dominated. Default effects, therefore, weighed against choice of a dominated plan. While we cannot distinguish enrollment into Plan 48 due to default from an active election, given intensive marketing effort prior to open enrollment, the firm reported that active choice of plans was high. Our estimate, based on the plan choice of new hires not subject to a default, and existing employees who were, is that the presence of a default led to an additional enrollment of 2 percent in the plan designated as the default. Stated differently, active choice was $98 \%{ }^{12}$ While there was a default option available for existing employees who did not visit the enrollment interface, the interface itself did not feature a default.

The online interface through which employees enrolled in a plan was designed to emphasize the sense that employees could "build" their own health plan feature by feature. Employees were asked to build candidate plans by sequentially selecting levels within each of four cost-sharing attributes, (e.g., "Which annual deductible meets your needs?”), after which plan features and the monthly cost was displayed. Employees were urged to consider the tradeoffs between price and coverage (e.g., "Remember,

\footnotetext{
11 Employees could change plan elections outside of open enrollment only in the event of a change in "qualified status" (e.g., birth of a child, or change in marital status).

12 If we estimate the probability of choosing the default plan (Plan 48) controlling for age and chronic conditions and an indicator for existing coverage, we find that those with existing coverage were 2 percentage points more likely to choose Plan 48 than similar new employees who did not have the default option.
} 
a lower deductible means higher annual paycheck costs"). After building a first candidate plan, employees had the option of enrolling in that plan or building subsequent plans which were then iteratively added to a plan comparison matrix. As such, the interface encouraged side-by-side comparisons of plans, but did not facilitate comparisons of marginal differences across plan attributes. The interface offered employees the option of viewing the entire plan menu in a link but it was not prominently displayed.

\subsection{Data on Plan Choice, Health Spending, and Employee Characteristics}

Overview of Data. For each benefit-eligible employee in 2010, the data include plan choice, medical utilization, and spending (subject to restrictions enumerated below), while for 2011, the data include only plan choice. Utilization data summarizes employee visits to a primary care physician, specialist, and ER and for preventative care. Medical-spend data reflects total medical expenses for each employee as well as the decomposition of spending into the share of employee's out-of-pocket expenses and the residual expenses covered by the firm. Importantly, the firm additionally estimated counterfactual medical spend, for both the member and firm, associated with each of the 47 plans not chosen by the employee (assuming fixed employee utilization). These estimates assume prices that are averaged across different locations and, as such, obscure any geographic price variation in prices. We obtained additional employeelevel demographic and health characteristics including age range, gender, salary band, location (3 digit zip code), start year of employment, position at the firm, length of firm tenure, and the presence of preexisting chronic medical conditions.

Sample Restrictions. Starting with the original set of benefit eligible employees, the firm generated a restricted sample for analysis using three screening criteria. First, in order to simplify the calculation of medical spending, the sample was restricted to employees continuously enrolled for the entirety of the plan year (June 2010 through end of May 2011). Second, for data integrity, employees who changed plans outside of open enrollment due to a life changing event were excluded. Finally, a small number of employees were excluded due to incomplete basic demographic information. The analysis presented in this paper is restricted to employees choosing single-coverage plans. A more extensive analysis, not reported here, suggests that employees choosing plans with expanded coverage behaved similarly to those described in the present analysis.

\subsection{Summary Statistics}

After imposing the sample restrictions, the resulting data describe plan choice, utilization, and medical care spending in PY 2010 for 51,192 employees, of whom 23,894 are employees with single-only 
coverage. Table 2 reports summary statistics for this latter sample. Overall, the sample is disproportionately female (71\%), and only $7 \%$ of employees were newly hired in 2010 . The average premium for employees, $\$ 1,205$, is in line with the $\$ 999$ national estimate for the average single-coverage employee premium in 2012, while the plans offered by the firm have lower deductibles than a typical firm of its size. ${ }^{13}$ The firm covers approximately $45 \%$ of total employee medical spending, and the average per capita employee spending of $\$ 3,567$ is slightly lower than the $\$ 4,547$ national per capita average for enrollees of employee sponsored plans. ${ }^{14}$

\section{SECTION 3. ANALYSIS OF PLAN CHOICE AND SWITCHING}

In the previous section we introduced the plan menu offered by the firm and described how the majority of plan options with lower deductibles were financially dominated. In this section we document employee choices and the financial consequences of those choices.

\subsection{Plan Choice Patterns}

Figure 2 presents histograms of plan choice by employees electing single coverage for 2010 . Despite the financial domination of nearly all plans with deductibles less than $\$ 1,000$ prior to tax adjustment, 63\% of employees selected a low deductible (Panel A). After tax-adjustment using the inferred marginal tax rate for each employee based on their reported salary range, 55\% of employees selected a plan that was financially dominated by another available plan option, and $27 \%$ of employees chose $\$ 350$ or $\$ 750$ deductible plans that were typically dominated by a large extent. The focus on deductibles alone, however, obscures meaningful patterns in plan choices. Panel B of the figure depicts the distribution of choice across all 48 plan combinations ordered by the degree of plan cost-sharing (by deductible, out-of-pocket maximum, coinsurance, and then copayment). The wide variety of chosen plans - every one of the 48 plans has a non-trivial share of enrollees - is evidence that the online enrollment process did not privilege the choice of any particular plan or plan attribute and further suggests that employees exhibited a range of plan preferences and/or search strategies. The single most popular plan was Plan 48, which was the least expensive, featured the highest degree of cost-sharing on all dimensions and was the default plan for those with existing coverage who did not choose a plan in the

\footnotetext{
${ }^{13}$ National averages are reported in the 2013 Kaiser Family Foundation study of Employer Health Benefits.

${ }^{14}$ Comparison is based on figures reported in the Health Care Cost Institute's 2011 annual report which is based on an analysis of medical claims data for approximately 40 million employees. The report is available at www.healthcostinstitute.org.
} 
new interface. As noted above, though we cannot unambiguously distinguish between those actively choosing Plan 48 from those defaulting into the plan, comparisons to new hires suggest that the vast majority of choices were actively made.

The choice patterns of Figure 2 reveal what appears to be a number of distinct strategies which govern the selection of plan attribute combinations. Among employees opting for the expensive $\$ 350$ deductibles, most appeared to minimize cost-sharing across all dimensions, and the most conservative, lower MOOP, lower copay and higher coinsurance option was the modal choice. Employees who chose the $\$ 500$ and $\$ 750$ deductible levels, in contrast, chose plans consistent with the desire to balance across cost-sharing dimensions. The modal plan for employees selecting both the $\$ 500$ and $\$ 750$ deductibles, for example, included the mid-level MOOP $(\$ 2,500)$. Ignoring the default option, such balancing is also evidenced among employees choosing the $\$ 1,000$ deductible where a significant share of employees chose the high-cost sharing MOOP $(\$ 1,500)$. This coherence in attribute patterns suggests that employees may have had some understanding of the tradeoffs between the level of coverage associated with plan attributes and plan premiums, a possibility which we explore in greater detail later in the paper.

\subsection{Savings from Counterfactual Plan Choice}

While characterizing the degree of dominated plan choice does not require knowledge of an employee's health spending, such spending is useful in assessing the financial consequences of these choices. For example, consider that for an employee paying an additional $\$ 501$ in premiums to lower the deductible from $\$ 1,000$ to $\$ 500$, the magnitude of ex-post excess spending due to plan dominance could be as high as $\$ 501$ or as low as $\$ 1$ depending on the employee's use of medical care for the year while exante excess spending would be somewhere between those values depending on expected medical need.

Figure 3 presents an analysis of the financial consequences of employee plan choices using data on health spending. Each panel in the figure compares the distribution of actual total employee spending (premium plus out-of-pocket health-care costs) to estimated spending given a distinct counterfactual plan choice. Counterfactual spending is calculated at the individual level for each employee on a tax-adjusted basis and assumes that the utilization of each employee would be unchanged across plans, or equivalently that employees are not subject to moral hazard in their utilization of care. Although health insurance plans with lower deductibles likely result in some degree of moral hazard, it is generally difficult to disentangle moral hazard from adverse selection (Einav and Finkelstein, 2011). If present in this setting, moral hazard would imply that our analysis would underestimate the financial consequences of plan choice. Such underestimation would arise since a share of the spending associated with low cost-sharing plans 
might be deemed unnecessary in the event of the shift to the high-cost sharing plan and could lead to even greater savings for such individuals.

The first panel of Figure 3 depicts potential cost-savings for each employee currently in a low deductible plan, relative to a switch to the otherwise equivalent plan with a $\$ 1,000$ deductible (i.e., same MOOP, coinsurance, and copayment). We show the empirical cumulative distribution of this ex-post net savings separately for each of the three low deductibles. The lines associated with the choice of $\$ 350$ and $\$ 750$ deductibles both start above $\$ 0$, indicating that, consistent with the earlier demonstration of dominance, all employees in such plans would have benefited from the prescribed plan switch. Among employees who chose plans with $\$ 350$ deductibles, the average savings amounts to $\$ 590$ with an interquartile range of $\$ 439$ to $\$ 843$. The top $10 \%$ (generally those with little to no health expenditures) would have saved over $\$ 1,000$. The average potential savings for those selecting plans with the $\$ 750$ deductible is $\$ 343$ (IQ range of $\$ 239$ to $\$ 430$ ), and for those choosing $\$ 500$ deductibles, the average savings is $\$ 159$ (IQ range of $\$ 102$ to $\$ 502$ ) inclusive of the $2 \%$ of employees with negative potential savings reflecting the absence of financial domination for all of these plans.

Overall, we find that the individuals who selected plans with deductibles lower than $\$ 1,000$ could have saved $\$ 353$ on average in after-tax dollars had they chosen the $\$ 1,000$ alternative with virtually no risk of losing money. ${ }^{15}$ Considering that over half of these employees have annual salaries below $\$ 30,000$, the $\$ 353$ in potential after-tax savings is likely of significant economic value. We calculate that the potential savings for employees selecting dominated plans represents an average of $2 \%$ of the employees' annual salaries and $42 \%$ of the annual premiums paid by the typical employee.

In Panel B we present a similar analysis but consider potential savings relative to the "actuarially best" plan associated with the lowest average spending across all employees (Plan 41 with a $\$ 1,000$ deductible, $\$ 2,500$ MOOP, 90\% Coinsurance, \$25 Copay). ${ }^{16}$ This exercise permits us to investigate the benefits of moving all employees to a single plan. While Plan 41 does not fully dominate the other options, $84 \%$ of all employees, and $97 \%$ of those with lower deductibles, would have benefited or been left no worse off, under the contemplated switch. Across employees, average savings would have amounted to $\$ 320$ including $\$ 448$ for those in low deductible plans, and $\$ 103$ for those with the $\$ 1,000$ deductible. The largest loss for any single employee under the projected switch is less than $\$ 1,000$ and no more than $5 \%$ of employees would lose more than $\$ 20$. These results suggest that, assuming fixed plan prices, an

\footnotetext{
15 The welfare value of those potential savings is quite similar even if we allow for substantial levels of risk aversion in a standard expected utility framework. Those calculations are available from the authors on request.

${ }^{16}$ Only $1 \%$ of employees actually selected this plan and 26 plans were chosen more frequently.
} 
informed third-party could have made a simple and generic plan recommendation that would have benefited the vast majority of employees.

Finally, we replicate the analysis but with Plan 48, the default plan option for employees and the plan with the highest cost-sharing, as the counterfactual plan. We estimate that such a plan switch would have benefited, or left unharmed, $85 \%$ of employees, and would produce an average savings of $\$ 182$ for these employees. As with the other counterfactuals, most of these savings would have accrued to those presently in low deductible plans, for whom savings would have averaged $\$ 283$. Relative to the other counterfactuals, the switch to this highest cost sharing plan would have generated greater risk of excess spending with a maximum increase in spending of about $\$ 1,600$ and with $5 \%$ of employees spending an additional $\$ 650$ or more. Nonetheless, the large share of employees, and particularly those currently with low deductibles, would have benefitted from simply being placed in the default plan.

\subsection{Heterogeneity in Choice and Adverse Selection}

The consequences of poor plan choice vary significantly across employees. Figure 4 displays the share of employees choosing dominated plan options by a primary dimension of interest - employee salary (Panel A). While a significant share of employees at every salary level chose dominated plans, employees in the bottom two salary bands (i.e., $\$ 0$ to $\$ 20 \mathrm{k}$, plotted as $\$ 10 \mathrm{k}$, and $\$ 20$ to $\$ 30 \mathrm{k}$, plotted as $\$ 25 \mathrm{k}$ ), representing over half of all employees, were disproportionately likely to have chosen dominated plans. Using the actuarial best plan (Plan 41) as a counterfactual, the second panel of the figure displays the average potential plan savings for each employee relative to employee salary (Panel B). For the 19\% of employees in the lowest salary band, the plot implies average savings amounting to over $4 \%$ of annual salary while for the $33 \%$ of employees earning from $\$ 20$ to $\$ 30 \mathrm{k}$ such savings represents $1.7 \%$ of salary.

Table 3 reports the heterogeneity in dominated plan choice across a broader set of employee characteristics. Each column represents a separate regression in which the dependent variable in the first column is an indicator for dominated plan choice, and in the final two columns is the magnitude of potential savings from a switch to a counterfactual plan (with premiums adjusted for tax deductibility in all cases). These regressions reinforce the pattern evident in Figure 4 in demonstrating a significant gradient in choice quality by salary - lower-salary employees were 24 to 30 percentage points more likely to choose a dominated deductible than the highest salary employees. Additionally, female employees were 6 percentage points more likely to choose dominated plans, and, conditioning on other characteristics, older, more highly tenured employees, and those with chronic conditions were all more likely to select dominated plans. Because the dominated plans in this setting are those offering the highest 
coverage (i.e., low cost-sharing), if people choose naively, the gender and age difference in decision quality may be consistent with prior work documenting the preference of females and older employees for low cost-sharing plans.

These results also highlight important patterns related to adverse selection in plan choice. In particular, the fact that older employees and those with chronic conditions are more likely to select lower deductibles, is indicative of adverse selection in employee-plan choice. We discuss these patterns of adverse selection and their importance for understanding the nature of insurance pricing we observe here in more detail in Section 5.

The second column of the table shows how these characteristics predict the expected counterfactual savings that employees could have achieved by switching to a $\$ 1,000$ plan deductible, holding other plan features constant. For this regression we include all employees and code the potential savings for those presently with a $\$ 1,000$ deductible as $\$ 0$ by construction. These estimates are consistent with earlier patterns with respect to employee income, age, and tenure, but reveal a different pattern for women and those with chronic conditions. Although these groups were more likely to choose plans that were financially dominated, they could expect to save less by switching to a high deductible plan given their higher relative levels of health spending. The final column considers the expected savings from a switch to Plan 41 and yields similar patterns to the choice estimates, and with generally larger marginal effects, which suggests that the same characteristics that predict the choice of a dominated deductible also tend to predict the choice of plans with lower average value on other dimensions as well.

\subsection{Employee Plan Switching}

Do employees improve plan choice over time? The stability of the plan menu permits us to examine whether employees improved plan choices the year following their original plan choices. In the second year of the build-your-own plan regime, the firm offered an identical set of plans to employees but with plan prices which increased by an average of 31\%. The change in plan prices led to a slight increase in plan dominance such that all 36 plans were financially dominated (on a tax-unadjusted basis). Employees, who were insured in 2010, but did not actively choose a plan in 2011 were defaulted into their existing plan.

Figure 5 summarizes switching behavior for employees by deductible choice. Overall, 77\% of employees kept their existing plan, consistent with numerous studies documenting consumer inertia in insurance choices (e.g., Strombom et al. 2002; Frank and Lamiraud, 2009; Sydnor, 2010; Handel, 2013; Ericson, forthcoming). Those with low deductible plans were more likely to switch plans relative to those 
with the $\$ 1,000$ deductible. However, switching rates for employees in $\$ 350$ and $\$ 750$ deductible plans, for whom the benefits of switching was the highest, were lower than those in $\$ 500$ deductible plans. Switching generally resulted in higher deductibles, but not always to the optimal $\$ 1,000$ deductible. On average, however, the moderate degree of plan switching we observed was beneficial with respect to plan dominance.

Finally, in light of the significant heterogeneity in choice quality by employee income, it is natural to ask whether lower or higher income employees are more likely to switch into efficient plans in the following year. We find that employees in the lowest two salary bands are actually significantly less likely to switch plans, with a switching rate of $18 \%$, relative to higher income employees who switch at a rate of $28 \%(\mathrm{p}<.01)$. Among those who do switch, low income employees are also significantly less likely to switch into the $\$ 1,000$ deductible. Indeed, the considerable plan inertia in this setting, if anything, serves to exacerbate the already substantial differences in choice quality across income groups.

\section{SECTION 4. MECHANISMS UNDERLYING POOR CHOICE}

Why would individuals choose financially dominated health plans? In this section we test candidate mechanisms for the observed behavior through a set of experiments in which we ask online subjects to make hypothetical health plan choices from stylized plan menus meant to reflect the choices made by employees.

\subsection{Candidate Explanations for Poor Plan Choice}

A first explanation we consider, in the first study, is whether search frictions generated by the complexity of the plan menu and the enrollment interface contributed to poor decisions. We broadly interpret such search complexity to encompass the large size of the plan menu (see Botti and Iyengar 2006 for a review of the "choice overload" literature), the number of attributes characterizing each plan, and the ease with which employees could compare plans. Search frictions may be particularly relevant in the setting we examine, given that the enrollment interface faced by employees may have discouraged appropriate plan comparisons.

We test two additional mechanisms through our second experiment. First, we consider whether poor plan choice is the result of deficits in health insurance literacy (e.g., Loewenstein et al. 2013; Handel 2013). We interpret literacy to include definitional knowledge of cost-sharing features (e.g., the ability to define and identify a plan's deductible and coinsurance rate), the conceptual ability to apply definitional 
knowledge to evaluate and compare the financial value of plans (e.g., given a set of plans for which other cost-sharing parameters are fixed, plan values can be compared by simply comparing the plan deductibles and premiums), and the computational ability to carry out required calculations. Second, we examine the possibility that poor choice may result from insufficient motivation on the part of employees to search and compare plans. Such a deficit might result from a false belief that the employer would not offer plan options of transparently lower economic value.

In a final experiment we explore the sensitivity of plan choices, in the presence of a largely dominated plan menu, to perceived health status and changes in plan prices. This experiment permits us to consider the degree to which individuals rely on the inputs-plan prices and health risk-typically expected to be relevant for plan choices. To the extent that individuals respond to trade-offs between dominated plan options as they would in the face of fairly priced menus suggests that plan selections may be the result of heuristic choice strategies.

Beyond the mechanisms which we test experimentally, the possibility exists that the observed behavior may, at least partially, reflect a sophisticated preference for financing health spending through payroll deductions rather than, more predictable, out-of-pocket expenses. This preference could result from the high costs of budgeting or liquidity constraints that make unexpected expenses difficult to manage. Models of non-standard risk preferences also predict demand for low-deductibles. For instance, individuals might rely on a separate "mental account" for expected monthly payroll contributions as compared to unexpected, and more hedonically painful, out-of-pocket expenses, (e.g., Prelec and Loewenstein 1998), may be subject to reference dependent preferences such that unexpected expenses are subject to loss aversion (e.g., Koszegi and Rabin 2007), or may be eager to avoid cost-sharing if they anticipate that such cost-sharing would lead them to underutilize valuable healthcare (Baiker, Mullainathan and Schwartzstein, 2013). Given that the typical employee who chose a dominated plan paid $\$ 631$ more relative to the high deductible option, and benefited by an average of $\$ 259$ in reduced out-of-pocket spending, for differential preferences across payroll and out-of-pocket dollars to rationalize the observed choices, employees must value an expected out-of-pocket dollar 2.4 times more than a dollar deducted from payroll. Moreover, the relief from unexpected expenses involves the marginal reduction of expenses over a very narrow range of out-of-pocket spending. For example, an employee choosing the $\$ 500$ deductible over the $\$ 1,000$ option only sees a reduction in out-of-pocket costs if total health spending is between $\$ 500$ and $\$ 1,000$. While we cannot definitely rule out this explanation, given the availability of alternative sources of financing almost certainly available to most employees, the narrow range of expenses over which the choice of a dominated plan might reduce out-of-pocket spending, and 
the high degree of literacy required to appropriately act on these preferences, we do not believe that a preference-based explanation is likely to account for a large share of the observed inefficiencies in choice.

\subsection{Experiment 1 - Search Complexity}

In our first study, conducted in June 2014, subjects were paid to take an approximately 10 minute survey in which they were asked to select an insurance plan from a hypothetical plan menu. The stylized menu featured fewer plans than the actual firm's menu but reflected the same degree of price domination. While our study was not incentive compatible, in similar studies other researchers have detected no differences in choice quality as a function of incentive compatibility (Johnson et al. 2013). The size and structure of the plan menu, as well the effort required to compare plans, was randomized between subjects in order to test how transitioning from a fairly complex interface, roughly approximating the firm environment, to a highly simple interface, influenced the quality of decisions. Appendix A overviews details of each experiment.

Subjects. The first study involved $N=2,379$ U.S. subjects drawn from the Qualtrics Online Sample. Of 3,895 subjects who began the survey, 1,516 subjects failed an early attention screen and were not invited to complete the instrument. ${ }^{17}$ The final sample, while not strictly representative of the US population, was diverse across gender $(57 \%$ female; $43 \%$ male), age $(M=46.5$, s.d. $=11.1)$, education (48\% college graduate; 33\% some college; $18 \%$ high school or equivalent), race (84\% white; $9 \%$ black; other $8 \%)$, and inferred income $(M=\$ 67,700$; s.d. $=26,900)$. Much like the employee sample in the main analysis, subjects were predominately full-time employees ( $91 \%$ full-time; 3\% part-time; $6 \%$ unemployed or student) who had employer-provided insurance (86\% employer insurance; $9 \%$ insured but not through employer; $5 \%$ uninsured). Overall, the experimental sample was older and wealthier than the employees in the main analysis.

Research Design. The study, hosted on the Qualtrics platform, required subjects to provide background information on their demographics and health, after which they were asked to imagine that they needed to select a (single coverage) health plan from a plan menu presented to them by their employer. The menu featured plans resembling those of the firm in price and in cost-sharing features, but featured fewer plans and were characterized by a smaller number of attributes. Mimicking the actual firm interface, subjects were presented with a table that defined each attribute and were instructed to

\footnotetext{
17 The screen involved a question with introductory text and 4 response options. The last line of the text asked subjects to not click on any response but instead, to simply click on next (unlike other forced-response questions, in this question, subjects were permitted to click "next" without indicating a response option). We pre-committed ourselves to not collecting any data from anyone who failed the attention screen.
} 
consider their expected health usage when choosing a plan. ${ }^{18}$ To test the link between choice quality and complexity, we randomized, in a conjoint design, the choice interface across three dimensions. The first was whether plan premiums were expressed annually or monthly. In the actual choice interface confronted by employees at the firm, premiums were presented on a monthly basis, whereas deductibles were for the year; we conjectured that this incompatibility may have made it more difficult for employees to evaluate the tradeoff between the two. Second, to test whether the inherent complexity of the insurance products may have played a role, we varied whether menus featured plans differing across two attributes (i.e., four deductibles and three MOOPs resulting in twelve options), or a single attribute (i.e., four deductibles resulting in four options). If complexity contributed to poor choice, then we should expect to observe lower quality choices with two attributes than with one. Third, in a condition designed to examine the impact of the company-provided web decision aid, we manipulated whether options were displayed simultaneously on a single table, permitting easy comparisons, or (as was the case in the Firm) displayed sequentially by attribute. ${ }^{19}$ In the latter condition, subjects were asked to make each attribute choice separately, after which the resulting plan price was displayed. Subjects could then finalize a choice or continue "building" another plan through the same sequential process, similar to what employees at the firm who used the company-provided decision aid experienced. ${ }^{20}$ Examples of interventions are displayed in the Appendix.

Results. An initial outcome of the study, which speaks to the ecological validity of the online study, is that the overall distribution of subject deductible choice resembled that of employees in the main analysis (Figure 6, Panel A). The second panel of the figure reports decision quality, reflected by the share of $\$ 1 \mathrm{k}$ deductible choice, across experimental interfaces varying from the complex analogue faced by firm employees (2 attributes, sequential choice, monthly premiums) to a highly simplified menu featuring four plans characterized by a single attribute and annual premiums. The share of nondominated plan selection across this gradation of complexity suggests significant gains from simplifying plan comparisons through the simultaneous display of plans $(\mathrm{p}=0.01)$. Further simplification through the display of annualized premiums, or the movement from 2 attribute choices (and 12 plans) to a single attribute (4 plans) did not improve choice quality. Although some of the experimental treatments had an effect, even in the condition that should have made it easiest for subjects to choose wisely — the one with

\footnotetext{
${ }^{18}$ Subjects were told that plans were equivalent apart from the attribute variation displayed in the menu, and that each plan included a "modest copay" for doctor visits.

${ }^{19}$ In the menu featuring plans varying across only deductible, subjects were told to assume a $\$ 1,500$ out-of-pocket maximum.

${ }^{20}$ We note, however, that while this condition was designed to most clearly mimic the setting at the firm we study, we suspect that introducing sequential choices is especially likely to cause low effort in a hypothetical setting, as there is no compelling reason for a subject to go back and "build another" plan.
} 
the simplest menu featuring 4 simultaneously displayed plans varying by deductible and annualized premiums - 66\% chose a financially dominated plan option; almost the same as the fraction of employees who chose dominated options.

Much like the employee setting, we observe considerable heterogeneity in the quality of choices by subject income. In a linear model of overall response across conditions, controlling for other observable demographics, we estimate that those reporting annual earnings of less than $\$ 50 \mathrm{k}$ make inferior choices to those earning greater than $\$ 80 \mathrm{k}(\mathrm{p}<0.05) .{ }^{21}$ Simplification also appeared to disproportionately aid subjects of low income (Panel C).

\subsection{Experiment 2 - Insurance Literacy and Search Motivation}

While the first study offers modest evidence of the role of menu and interface complexity on choice quality, our second experiment presented subjects with relatively simple plan menus, to investigate whether literacy of health insurance concepts and economic motivation to scrutinize plans affects decision quality. The study, therefore, scrutinizes the possibility that it may not be the complexity of plan search, but the more fundamental complexity of the structure of insurance that leads to inefficient choice.

Subjects. The second experiment, conducted in July 2014, involved $\mathrm{N}=624$ U.S. subjects recruited from the same panel as the first study and subject to the same attention screen. The final sample again reflects a diversity of gender $(56 \%$ female), age $(M=49.8$, s.d. $=12.3)$, education $(39 \%$ college graduate; $38 \%$ some college; $21 \%$ high school or equivalent), race ( $86 \%$ white; $7 \%$ black; other $7 \%$ ), and inferred income $(M=\$ 50,600$; s.d. $=30,700)$. Subjects in the second study were more diverse in employment (43\% full-time; 13\% part-time; 43\% unemployed) and insurance status (37\% employer insurance; $52 \%$ insured not through employer; $12 \%$ uninsured) than either the original study or the empirical sample.

Research Design and Protocol. The second experiment featured a similar structure and design as the first study but included assessments of literacy and beliefs. The former was implemented by presenting subjects with a short narrative scenario of a recent health insurance enrollee in which they were asked to identify various health insurance concepts (i.e., deductible, out-of-pocket maximum, coinsurance and copayment). We assessed subject beliefs regarding the likelihood that they would be offered plan options of low financially value by asking: "When enrolling in health insurance, typically you would be asked to choose from a set of health plans with very different prices (premium). What

${ }^{21}$ We elicited income in five ranges, but we consolidate the highest two income categories (income greater than $\$ 120 \mathrm{k}$, and income between $\$ 80 \mathrm{k}$ to $\$ 120 \mathrm{k}$ ) for increased power and analytic tractability. 
would you expect to be true about these plan options?" Subjects could indicate that the price differences usually reflect differences in quality or coverage ("you get what you pay for"), do not reflect such differences ("many plans are simply a bad deal"), or uncertainty about what to expect.

To experimentally test whether improving health literacy and search motivation might affect choice quality, subjects were randomized into one of three conditions in which they were asked to make a choice first from a menu with 4 plan options (varying by deductible) and then from a menu with 12 plan options (varying by deductible and MOOP). All menus featured low deductible options which were dominated by the highest deductible plan. Prices were approximated from the firm menu, but differed nominally across the two menus to avoid presenting subjects with identical plans. In the control condition, subjects were simply asked to make the two plan choices. In a second condition, we attempted to manipulate search motivation by displaying a screen prior to the choice screen which informed subjects that the options were not designed to be appropriate for everyone and that poor plan choice could lead to additional spending of nearly $\$ 500$ annually. In a final condition, subjects were guided, prior to the choice, through a scenario-based tutorial offering instruction as to how to compare the financial value of plans, including a quiz, and a "rule-of-thumb" to help subjects avoid financially dominated plans. ${ }^{22}$

Results. A majority of the study subjects did not report suspicions that plan menus contain options of low economic value. ${ }^{23}$ As evident in Figure 7 Panel A, subjects who believed that offered options might differ in their price-quality tradeoff (i.e., subjects included in the bars marked "Suspicious") were only marginally more likely to choose non-dominated options than "Trusting" subjects (in the single attribute choice, pair-wise comparison not significant; in the two attribute choice, pair-wise comparison, $\mathrm{p}<0.10)$. Finally, as can be seen in Panel B of the same figure, cautioning individuals that the choice they face may be consequential (bars labeled "motivate") did not improve choice relative to subjects in the control group. In sum, while we document widespread ignorance of the possibility of dominated plan options, we find only weak support for the possibility that such ignorance is alone mediating poor plan choice.

Turning to the impact of literacy, consistent with earlier studies, we find that $71 \%$ of subjects were not able to identify the basic cost-sharing features from a simple health scenario. ${ }^{24}$ Moreover, literacy, was highly predictive of subject ability to detect dominated plan options (both pairwise

\footnotetext{
22 Subjects were informed that if other plan features were identical, a dominated plan can be detected by comparing the difference between plan deductibles and plan premiums.

${ }^{23} 28 \%$ expected plans to typically feature such options, $54 \%$ believed that price differences typically reflect quality differences, and $18 \%$ were unsure.

${ }^{24}$ We counted inverted responses for the coinsurance question as correct, otherwise $82 \%$ of participants failed to identify the four costsharing principles correctly.
} 
comparisons, $\mathrm{p}<0.01$ ), as can be seen in the right hand graph of Panel A. Providing further support for the importance of literacy, the information intervention aimed at improving literacy (see Appendix for details of the intervention) significantly improved choice quality relative to the control (both questions, $\mathrm{p}<0.01)$. Moreover, as revealed in Panel C, the education intervention led to larger relative increases in response quality for those of low, as compared to high, baseline literacy. As in the first study, we observe a ceiling in choice quality in that thirty to forty percent of subjects persist in poor choices even with a fairly aggressive intervention designed to improve choice.

\subsection{Experiment 3 - Responsiveness of Choices to Plan Price and Perceived Health Status}

The first two experiments found that a majority of subjects chose dominated options even when faced with extremely simple menus. While most subjects suffer from low plan literacy, our empirical analysis of the employee data shows correlations between choices and health status that suggest those choosing dominated options are not just choosing randomly. In our third study we more directly explore the considerations that shape insurance demand by examining the sensitivity of choice the perceived health risk of subjects and to price differences between plans, across menus with many dominated options.

Subjects. The third experiment, a 15 minute online instrument, was completed by a sample of $\mathrm{N}$ $=734$ subjects recruited from Amazon Mechanical Turk in December 2014. The sample was again diverse across demographic characteristics such as gender (49\% female; 51\% male), education (49\% college graduate; $40 \%$ some college; $10 \%$ high school), and race (76\% white; $7 \%$ black; $17 \%$ other) but is somewhat younger $(M=36.5$, s.d. $=12.0)$, and of lower inferred income $(\$ 40,940$, s.d. $=19,117)$. 80\% of subjects had health insurance, and 59\% were employed full time.

Research Design and Protocol. The study was similar in structure to earlier experiments in capturing a range of demographic characteristics, but included a number of additional questions designed to assess perceptions of subject healthiness relative to peers ("Extremely Healthy", "Fairly Healthy", "Somewhat Healthy", "Unhealthy”), financial literacy, using two commonly used elicitations as discussed by Lusardi (2008), as well as a series of other questions constructed for a separate research study on risktaking. ${ }^{25}$ The survey's main outcome of interest was plan choice from a simple menu featuring four plans characterized by a deductible and an annual premium (and otherwise identical). As can be seen in Table

\footnotetext{
25 The study was a part of a larger survey originally administered for separate on-going research examining risk preferences and driving behavior conducted by Bhargava and other coauthors. Subjects in this survey were screened on ownership of a vehicle and were restricted to those 21 years and older.
} 
4, in a first condition, we presented a menu featuring four popular plans from the firm's menu (Plans 46, 34,22 , and 10) which spanned the range of available deductibles $(\$ 350, \$ 500, \$ 750, \$ 1,000)$ and shared other cost-sharing features. In the second condition ("More expensive"), we fixed the annual price of the $\$ 1,000$ deductible ( $\$ 817$ ) but increased the costliness of reduced cost-sharing by pricing the low deductible plans so that the marginal cost of each dollar of reduced deductible, relative to the highdeductible option, was $125 \%$ of the original marginal cost. That is, while the original $\$ 750$ plan cost $\$ 1321$, or $\$ 504$ more than the $\$ 1,000$ plan, in the expensive condition, this plan was priced at $\$ 1447$ which reflects a $\$ 630$ differential. In a third condition ("Less expensive”) we adjusted prices so that the marginal cost of a reduced dollar in deductible was only $75 \%$ as costly as the original marginal cost. Across these conditions, low-deductible plans in the baseline and expensive conditions were financially dominated by the $\$ 1,000$ plan, while in the cheap condition the $\$ 500$ deductible plan fell $\$ 49$ short of being dominated (price difference of \$451).

Results. Figure 8 summarizes the result of the third experiment. Panel A shows that subjects were moderately responsive to the price differentials across the different treatments despite nearly all of the lower deductible options being dominated across all treatments. The fraction of subjects choosing the $\$ 1,000$ deductible is around 11 percentage points higher in the "More expensive" treatment than the "Less expensive treatment" ( $p<0.03$ ). Importantly, this price elasticity is similar to that observed by Einav, Finkelstein and Cullen (2010) for employees choosing from menus that do not include dominated options. Einav, Finkelstein and Cullen (2010) estimate that every dollar of additional premium reduces the share of individuals willing to pay to eliminate an in-network deductible by $\$ 500$ by 0.0007 . If we consider the differential demand for the $\$ 500$ and $\$ 1,000$ deductibles (a difference in $\$ 500$ in cost-sharing) among subjects in the experiment, the reduction in the share purchasing the lower deductible yields a similar 0.0005 per additional dollar in premium. Consistent with the correlation in health status and plan choice exhibited by employees, Panel B shows that subjects' perceived health status strongly predicts the choice of deductible. The $24 \%$ of subjects who perceived themselves to be extremely healthy were significantly more likely to choose the $\$ 1,000$ deductible option than those with lower perceived health status $(51 \%$ vs $33 \% ; \mathrm{p}<0.01)$. Not depicted in the figure, the $16 \%$ of subjects who viewed themselves as only "Somewhat Healthy" or "Unhealthy" were significantly more likely than their counterparts to opt into the lowest available deductible $(\mathrm{p}<0.05)$.

The results of this experiment suggest that subjects, when faced with menus involving financially dominated options, attend to the same key determinants of plan price and health risk in determining their demand for insurance than they would in menus with plans that are reasonably priced. As with the 
employees in the main analysis, subjects do not appear to make choices randomly, but instead appear to recognize the existence of tradeoffs involving plan prices and health risk. Such coherence with respect to plan tradeoffs may ultimately be naïve, however, given that it is exercised without regard to the underlying financial value of plans in a particular menu.

\subsection{Discussion of Mechanisms}

The experiments offer a number of insights into the mechanisms underlying plan choice. First, while there are modest benefits to simplifying search by facilitating plan comparisons (Experiment 1), even with highly simplified menus featuring a small number of plans and plan attributes, a majority of subjects fail to detect dominated plans. Moreover, the widespread lack of health insurance and financial literacy, and low awareness that menus might feature dominated plans, support the likelihood that most employees were unable, or perhaps unmotivated, to rigorously compare the financial value of plans (Experiment 2). Despite their economic inefficiency, however, the choices of study subjects display the same non-random character of those made by employees, including peaks in demand for $\$ 500$ and $\$ 1,000$ deductibles and correlations with health risk.

Overall, these experiments suggest that the costly choice of dominated options is not driven by the complexity of the enrollment interface but by a more fundamental challenge of sensibly comparing the economic value of different plan options. Faced with plans that are difficult to compare, due in large part to deficits in basic insurance literacy, individuals might be expected to choose randomly- instead we find consistent patterns in choice that seem to reflect recognition of the trade-off between plan price and plan coverage. That the healthiest and sickest individuals sort themselves into the least, and most, generous of plans, without much consideration for the overall differences in plan value (i.e., the

comparison between differences in coverage and average plan costs), suggests that individuals may be employing a heuristic choice strategy in which individuals sort into available plans based on perceived need and the marginal differences in plan prices but not a full financial comparison of plans. Such a strategy, while potentially reasonable when menus are fairly priced to the individuals, leads to costly poor choice in the presence of menus with dominated options. The possibility of such heuristics is hinted at by a range of studies that have demonstrated the sensitivity of choices to the configuration, or framing of the choice menu (e.g., Tversky and Kahneman 1974; Slovic 1995; Ariely, Loewenstein, and Prelec 2003), research that suggests that, in the absence of fully formed preferences, individuals may rationally infer the appropriate choice from the information contained in the choice menu (Kamenica 2008; Prelec, 
Wernerfelt, Zettelmeyer 1997, Kamenica, 2008), or may be drawn to relatively salient choices in such a menu (Bordalo, Gennaioli, and Shleifer 2012).

\section{SECTION 5. UNDERSTANDING THE PRICING OF PLAN OPTIONS}

A natural question is why a firm would offer its employees dominated health insurance options. All the evidence we have is that they were unaware of doing so. In this section we speculate about how this happened, proposing that the provision of dominated options was a natural consequence of substantial adverse selection, average cost pricing, and the expansion in plan choice over narrow ranges of cost-sharing.

\subsection{Actuarial Practice and Average Cost Pricing}

In establishing the build-your-own platform, the firm partnered with an actuarial/healthinsurance consulting firm to help price the plan options. As Handel (2013) notes, the standard actuarial practice for plan pricing centers around the calculation of average insurer costs (i.e., covered insurance payouts) across plan options. Handel (2013) studied the evolution of plan pricing at a large firm and concluded that the considerable adverse selection in initial employee plan choice combined with price adjustments updated to reflect average-cost differences caused certain plans, which were not initially dominated, to become financially dominated as pricing gradients widened.

Table 5 presents a series of regressions to explore the consistency of our firm's menu with such an average-cost pricing strategy. In the first column of the table we regress each of the 48 plan premiums on indicators for different cost-sharing features, omitting the highest-cost sharing option in each category. These estimates capture the marginal difference in plan price associated with each cost sharing feature. For example, plans with $\$ 500$ deductibles cost an average of $\$ 625$ more than the equivalent plan with a $\$ 1,000$ deductible which is consistent with the earlier discussion of plan dominance. While the pricing of the firm menu may reflect more complicated interactions, the simple regression, with an R-square of 0.99, explains most of the observed variation in prices across plans.

The second column of the table estimates how the average incremental cost to the insurer (i.e., employer) for the employees who selected that coverage is related to each cost-sharing attribute. This regression shows how the amount of covered spending for an employee is affected by the different costsharing options. Comparing Column 2 to Column 1 confirms the large potential savings from avoiding dominated deductibles. The estimates show, for example, that, all else equal, employees have to pay an 
average of $\$ 625$ to lower the deductible from $\$ 1,000$ to $\$ 500$, but such a shift would save the employees who select that coverage an estimate of only $\$ 230$ through reductions in out-of-pocket spending (equivalently, increases in covered spending). In every case, except for the $90 \%$-coinsurance versus $80 \%$ coinsurance comparison, the premium differences employees face for additional coverage exceed the expected out-of-pocket savings the employee would see from that additional coverage.

The third column of the table suggests that the observed pricing appears more reasonable if one were to rationalize premium differentials by attending to differences in the average total costs to the insurer associated with each plan. This column reports a regression of average total medical spending covered by the insurance on plan features for those employees selecting into each plan. The coefficients from this regression reflect both the incremental cost to the insurer for covered health spending (Column 2), as well as differences in total health spending between employees by plan choice. Consistent with the adverse selection documented in Table 3, the regression implies large differences in total insurer cost for individuals selecting additional coverage on each dimension of cost-sharing. As illustration, employees choosing plans with $\$ 500$ deductibles generated an estimated $\$ 1,211$ more in total insurance costs than those choosing higher deductibles, all else equal. A comparison of the average total insurer costs from the final column against the corresponding employee costs reported in the first column suggests that the large price differentials can be at least partially rationalized by differences in average cost of each plan to the insurer. Figure 9 displays how the premiums from the firm menu reflect an approximately equal share of covered health spending (e.g., "total premium”) paid by the employee (i.e., "employee premium”) across plans. We estimate that, on average, this share is just over $40 \%$ across plans associated with each cost-sharing feature.

These results suggest two intriguing implications for the economic consequences of plan choice. First, the consequences of poor choices for less sophisticated employees could be diminished if, rather than reflecting differences in average total cost, price differentials between plans were capped at the average incremental cost of providing additional coverage. Such a policy would ensure that pricing would never violate dominance. Second, simply educating the employees to make more sensible plan comparisons, and in this case encouraging the choice of $\$ 1,000$-deductible plans, while clearly beneficial to the employees making the largest mistakes, is likely to lead to more muted benefits if the firm adjusts prices in accordance with average cost pricing. 


\subsection{Average-Cost Pricing and Dominated Plan Menus}

The prior analysis of plan pricing offers insight into how a menu featuring expensive highcoverage plans might emerge from standard pricing practices. The emergence of a menu with plans of widely ranging financial value additionally requires the assumption that firms are able to accurately forecast the extent to which employees sort by health risk into plans, and, at least implicitly, that employees would fail to recognize or negatively react to exaggerated plan prices. ${ }^{26}$ While seemingly reasonable, this interpretation raises the question of why dominated plan menus, of the sort we analyze in this paper, are not more pervasive across insurance settings with significant adverse selection. While prior work has documented the regularity that insurance menus with low-cost sharing plans tend to be highly priced (e.g., Einav, Finkelstein and Cullen 2010; Handel 2013), we are not aware of evidence that menus with severely dominated plan options are widespread.

A potential explanation for this puzzle may be that the firm's efforts to expand employee choice through the "build-your-own" plan regime was overly ambitious. The plan menu generated by the firm permitted employees to choose between plans that differed only in their deductible, while most employersponsored plans bundle together multiple cost-sharing features. The consequence of such plan flexibility is that employees were permitted to sort across plans which differed in cost-sharing only along the narrow dimension of a deductible. In the presence of average-cost pricing, expected differences in health spending across employees by deductible choice, due to sorting by health risk, would generate large differences in plan prices that could easily lead to dominated pricing. In traditional settings, where differences in deductibles are typically associated with differences in other cost-sharing attributes (e.g., MOOP), price differentials driven by anticipated employee sorting can be supported by a wider range in cost-sharing, and, as such, are less likely to yield dominated plan menus.

As a simple illustration of this point, consider if our firm had only offered the two plans with greatest and lowest cost-sharing (i.e., Plan 48 and Plan 1). Suppose employees presently choosing the $\$ 350$ or $\$ 500$ deductible, would sort into Plan 1 (\$350 deductible, $\$ 1,500$ MOOP, 90\% Coinsurance, and $\$ 15$ Copay) under the new regime, and that those presently with $\$ 750$ or $\$ 1,000$ deductibles would sort into Plan 48 (\$1,000 deductible, \$3,000 MOOP, 80\% Coinsurance, \$25 copay), Based on the counterfactual estimates of plan spending, the firm's share of average health-care spending would be $\$ 3,847$ for Plan 1 and $\$ 1,849$ for Plan 48 . If the firm required employees to pay premiums that cover

${ }^{26}$ Given the wealth of information actuarial consulting firms have about health-care use across plans they help to design and administer for different companies, it is not particularly surprising to us that they would have good projections that capture the type of risk sorting we see here. 
$40 \%$ of their expected covered spending (consistent with Figure 9), this would suggest a premium difference of $\$ 799$ between the two plans. For the individuals sorting into Plan 1 over Plan 48, the marginal difference in health spending that would be covered would be, on average, $\$ 622$. Although the differential price of $\$ 799$ for Plan 1 would far exceed its expected value, Plan 48 would not dominate Plan 1 in this scenario since the maximum potential reduction in out-of-pocket spending for the employee is over $\$ 2,500$ and, indeed, $28 \%$ would benefit ex-post from enrollment into the more expensive plan.

\section{SECTION 6. IMPLICATIONS FOR ANALYSIS OF INSURANCE MARKETS}

A significant literature has emerged which analyzes consumer choices in insurance markets, and health-insurance markets in particular, using individual-level data on observed choices from plan menus that vary in both price and cost-sharing provisions (see Einav, Finkelstein and Levin, 2010 and Einav and Finkelstein, 2011 for reviews). While the observed menu offered to the employees in our analysis is unique for having many dominated options-indeed, it is such uniqueness which permits us the rare opportunity to cleanly evaluate plan choice quality—we believe that the economic and psychological factors identified in this setting are widespread. With respect to firm behavior, in the previous section we documented that the prices we observe are consistent with the common practice of average-cost pricing coupled with a particular manner of implementing the also common trend towards expanding the choices available to consumers. With respect to consumer choice, the willingness of our employees to choose low deductible plans is consistent with prior studies in which employees have shown a strong preference for more generous plan coverage (Einav, Finkelstein and Cullen 2010). ${ }^{27}$ Moreover, the relative insensitivity to price differentials we document in Experiment 3, where individuals made choices involving dominated menus, is quite close to estimates from Einav, Finkelstein and Cullen (2010), in which employees made choices from plans which did not feature strict financial domination. To clarify the implications of our study for the broader literature, we use the graphical framework developed by Einav, Finkelstin and Cullen (2010) to show how choice predictions from standard insurance models differ once we permit consumers to make decisions which reflect a more heuristic choice process broadly consistent with the patterns we observe.

\footnotetext{
27 The authors document that nearly half of Alcoa employees were willing to pay $\$ 570$ additional premium to lower their in-network deductible from $\$ 500$ to $\$ 0$ (and out-of-network deductible from $\$ 1,000$ to $\$ 500$ ) and that this willingness was efficient, ex-post, for about $6 \%$ of employees.
} 


\subsection{Analysis of Insurance Markets within Standard Model}

The standard approach in the literature on insurance demand starts from a canonical model in which individuals select insurance coverage based on their anticipated risk and preference for risk aversion. Willingness to pay for insurance in the standard model emerges from the value of reducing the variance of spending. Following the exposition and notation in Handel and Kolstad (forthcoming), we can denote an individual's utility for a health-insurance plan as:

$$
u_{j k}=\int_{0}^{\infty} f_{k j}\left(s \mid \varphi_{j}, \mu_{k}\right) u\left(W_{k}-P_{k j}-s, \gamma_{k}\right) d s
$$

where $u_{j k}$ is individual k's utility under plan $j, P_{k j}$ is the premium the individual must pay for the plan, $W_{k}$ is initial wealth, $f_{k j}\left(s \mid \varphi_{j}, \mu_{k}\right)$ is the probability density of out-of-pocket costs for the individual in that plan -- which depends on the cost-sharing provisions of the plan $\left(\varphi_{j}\right)$ and the individual's ex-ante health risk $\left(\mu_{k}\right)$-- and $\gamma_{k}$ is the individual's coefficient of risk aversion. The standard approach assumes that individuals select the available plan which maximizes utility given accurate beliefs about the financial consequences of choices and ex-ante health risk.

In Panel A of Figure 10 we present a graphical analysis following Einav, Finkelstein and Cullen (2010) based on a very simple simulation of choices over two health plans that vary only in deductible, with options of $\$ 1,000$ or $\$ 500$. We assume that all costs above the deductible are fully covered, individuals have private information about their probability of experiencing a health shock $\left(\pi_{k} \sim U[0.01,0.99]\right)$, and that total medical spending (covered + cost-share) is $\$ 3,500$ when a health shock occurs and $\$ 0$ otherwise. While this process is clearly a rough approximation of that which might generate true medical spending, it is meant to reflect a realistically wide variation in underlying health risk of consumers. Finally, we assume that individuals have CARA utility functions, with coefficient of absolute risk aversion parameters (independent of health-shock probabilities), $\gamma_{k} \sim U[0.0001,0.003]$, which implies both high degrees of risk aversion on average and substantial heterogeneity in risk aversion. ${ }^{28}$ We draw 20,000 combinations of risk type and risk aversion from these distributions and then record which of the two plans the individual would choose based on the expected utility formula above for a range of plan price differences.

The first panel of the figure corresponds to the analysis in Einav, Finkelstein and Cullen (2010) and shows both a downward sloping demand curve and also a downward sloping incremental average cost curve, which reflects the adverse selection that occurs when people select coverage based partly on

\footnotetext{
${ }^{28}$ The mean risk aversion parameter from that distribution matches the average estimated coefficient of absolute risk aversion required to rationalize health-plan selections in Handel and Kolstad's (forthcoming) baseline case before accounting for informational frictions and inertia.
} 
information about their health risk. Point $\mathrm{A}$ in the figure represents the efficient level of insurance where marginal cost equals demand. Since everyone in the simulation is risk averse and has accurate beliefs about their expected health risk, willingness to pay is always at least as high as the expected marginal cost of the additional insurance. If price levels converge in equilibrium to the average incremental cost of additional insurance coverage, the equilibrium will instead be at point $\mathrm{B}$ in the figure, resulting in a deadweight loss due to the distortion of adverse selection on prices given by the shaded region in the figure. The potential equilibrium price is $\$ 340$, which reflects that the probability of a health shock is on average 0.68 for those purchasing the additional $\$ 500$ in coverage $(340=0.68 * 500)$.

While this equilibrium is the primary focus of the analysis in Einav, Finkelstein and Cullen (2010), the figure also highlights that in situations where individuals choose plans that vary in their degree of cost-sharing, the difference in the total average cost of providing insurance to groups selecting the different plans can be much higher than the average incremental cost of additional insurance. In the graph we see that at the potential equilibrium point $\mathrm{B}$, the average total cost of providing insurance to those with the lower deductible, point $\mathrm{D}$, is much higher at $\$ 1,460$. The difference in average total cost reflects not only the expected additional insurance coverage (\$340) but also the difference in coverage that would have occurred at the higher deductible for these groups $\$ 2,500$ in spending multiplied by group-level average differences in the probability of a health-shock). It is possible that in the absence of regulation or other price controls that market forces or standard actuarial prices might push price differences toward these average total cost differences. However, as we see in the graph, if prices rise the market will quickly unravel to point $C$, where no one purchases the lower deductible, since rational consumers here will never pay for coverage at dominated prices. Achieving a point like Z, which reflects our empirical and survey findings, is simply not possible within the standard framework.

This discussion highlights the relevance of our study for understanding the dynamics of risk sorting that we might observe in competitive markets or employees-sponsored plans where individuals are asked to choose plans that vary in their cost-sharing. Rothschild and Stiglitz (1976), and the research that followed, highlighted that competitive insurance markets could exist even in the presence of adverse selection by allowing different risk types to sort into separate contract options that reflect their differences in risk. However, this work also warned that with too much risk-heterogeneity in the population, offering many options might lead the market to unravel. With only very small differences in cost-sharing (e.g,. deductible differences of \$500), standard theory would predict the impossibility of supporting an equilibrium in which there is substantial sorting by risk type. In order for such an equilibrium to emerge, high-risk consumers would have to be willing to pay extreme costs for only modest expansions in 
coverage. The choice patterns we observe suggest that high-risk individuals may lack sophistication in their evaluation of plans and that poor choice quality may lead to stable separating equilibria even over very small cost-sharing differences. ${ }^{29}$ If true, in the absence of regulation on pricing or other risk-pooling transfers, sophisticated Ohealthy consumers may be able to avoid cross-subsidizing less healthy individuals who are unsophisticated about insurance without sacrificing much in the way of insurance coverage.

\subsection{Incorporating Heuristic Choice into the Analysis of Insurance Markets}

Standard insurance models are unlikely to predict the existence of equilibrium points such as $\mathrm{Z}$ in Figure 10. Handel and Kolstad (forthcoming) incorporate a range of informational frictions into the standard model and discuss how such amendments have implications for welfare analysis. However, the informational frictions they introduce are not likely to rationalize the choices we observe given that employees and experimental subjects violate dominance even in the face of transparent differences across contracts that vary on simple cost-sharing dimensions. The high willingness to pay for low deductibles and low elasticity of demand with respect to price could potentially be rationalized given substantial noise in how consumers evaluate cost-sharing features, yet such noise would also suggest a lack of correlation between choices and risk types. We present an alternative strategy for amending the standard model which is more consistent with the heuristic-choice process suggested by our experimental evidence. While this is not a formal modeling exercise and we doubt the simple model here captures the more complicated psychology underlying actual decisions, it offers insights into how the incorporation of heuristic choice strategies may substantially influence the analysis of insurance markets.

Drawing on the findings from our experiments, we first assume that consumers are largely, but not completely, inattentive to price differences when making plan choices but fairly sensitive to their risk type. A simple way to model this process is to assume that the perceived expected utility of a plan option is a convex combination of the actual expected utility of the plan and the expected utility of the plan under the naïve (and inaccurate) assumption that prices reflect actuarially fair cost to the employee. Under this assumption the perceived utility of a plan choice is:

$$
\tilde{u}_{j k}=(1-\theta) u_{j k}+\theta \int_{0}^{\infty} f_{k j}\left(s \mid \varphi_{j}, \mu_{k}\right) u\left(W_{k}-\bar{P}_{j}-s, \gamma_{k}\right) d s
$$

\footnotetext{
${ }^{29}$ A further important consequence of these dynamics is that apparent stability of health-insurance markets could be highly misleading. In particular, if one were able to introduce an effective decision aid into a situation like the one we observe, we would likely see a massive and rapid change in consumer choices. It may be, then, that markets that appear initially stable may collapse and unravel suddenly if unsophisticated consumers are better informed about available options.
} 
where $\bar{P}_{j}$ is the actuarial fair price to the consumers for the coverage in the population and the parameter $\theta$ is a price-inattention parameter that lies between 0 and $1 .{ }^{30}$ As $\theta$ goes to 1 individuals use only a simplifying heuristic where they do not need to evaluate the actual prices of policies and instead for any given risk-aversion level can simply choose based on their ex-ante risk type.

In Panel B of Figure 10 we present the results of a simulation of this model using the same parameters as the analysis in our standard-model simulation but incorporating a $\theta$ of 0.85 , which is chosen so that the observed demand passes through point $Z$ on the curve. Because individuals are still sorting largely based on ex-ante health risk, the observed incremental average cost remains downward sloping and is in fact very close to the average cost curve from the standard model. The difference, however, is that inattention to price causes the demand curve to be very steep. In this example, if one were to apply the type of analysis developed by Einav, Finkelstein and Cullen (2010) to choices produced by this heuristic choice process, one would estimate the efficient quantity of insurance at point $A^{\prime}$ and the equilibrium price at B'. The measured welfare loss (shaded region) would suggest an average welfare loss of $\$ 2.93$ per individual. However, the true welfare loss at this point, as measured from the underlying model parameters (i.e., WTP from the original equation), would instead be $\$ 16.42$. The standard analysis would understate welfare losses by a factor of five, primarily because the price-insensitive demand curve leads one to conclude that the efficient level of insurance is much lower than it actually is.

While our analysis, and this example in particular, point to the importance of understanding the role of decision heuristics and biases in the choice of insurance, Panels A and B also offer simple indicators to which researchers can appeal to identify when non-standard preferences are likely to be critical for analysis. The first, and most obvious, indicator is when estimated demand curves predict violations of dominance. A second, more subtle, indication that consumer biases may be strongly influencing decisions is when the efficient level of insurance $(\mathrm{MC}=\mathrm{D})$ projected by an analysis like this does not involve full insurance. Indeed, a setting in which a substantial share of consumers value insurance less than its marginal cost - a pattern that appears to characterize the employees in the analysis reported by Einav, Finkelstein and Cullen (2010)_implies that such consumers are either risk-loving or suffer from inaccurate beliefs regarding their health risk. ${ }^{31}$

\footnotetext{
30 This type of behavioral model where utility is a convex combination of the standard model and a biased utility level is common in the behavioral economics literature (see DellaVigna, 2009 for a review), and this particular formulation shares much in common with the cursedness framework of Eyster and Rabin (2005)

31 This assumes that the analysis measures marginal cost based only on insured claim differences and not other inputs to claims-processing costs, which is consistent with our example here and the empirical analysis in Einav, Finkelstein, and Cullen (2010).
} 


\section{SECTION 7. CONCLUSION}

Our principle contribution is to document widespread and costly violations of dominance in the health-insurance decisions of a large and diverse sample of U.S. employees. Unlike most prior work, our paper is able to transparently assess choice quality without making assumptions about risk preferences or beliefs, by analyzing employee choice from a standardized plan menu with a large share of financially dominated options. For the majority of employees who chose dominated plans - a disproportionate share of whom were of low income-the adverse financial consequences of poor choice outweigh the estimated benefits of recent policy measures (e.g., the effect of the exchange on insurance premiums, or the penalty associated with the individual mandate) that have attracted far more policy attention.

Our initial results prompted us to address the question of why employees make such disadvantageous decisions. Through a series of online experiments with hypothetical choices modeled on the firm's plan menu, we find evidence for a modest role of search/menu complexity and much larger role of low health literacy. Confirming other research, we find widespread deficits in employee understanding of the insurance choices they face. Even with simple menus with few options, we observed significant errors in plan choice, suggesting that plan choice is difficult to improve. The online studies suggest that poor choice may partly reflect a heuristic understanding of health insurance such that consumers sort into plans based on perceived health risk and inferences about plan generosity from the rank-ordering of plan deductibles rather than a careful assessment of financial plan value.

The promise of recent reforms that expand choice and aim to increase provider competition is premised on the assumption—challenged by our research— that enrollees will make sensible plan choices. While efforts to improve choice through simplification, education, and other modifications to the choice environment may improve the quality of decisions, our results suggest value in shifting focus from helping consumers navigate complicated insurance options to simplifying and standardizing the options themselves. At the extreme, if all firms offered identical products, then competition would be far more likely to focus exclusively on price and quality. Beyond implications for policy, our study asserts that traditional attempts to infer risk preferences from health insurance choices may be misguided. Rather than reflecting rational deliberations involving cost, need, and risk, many health plan choices likely reflect heuristic choice strategies grounded in a fundamental deficit of health plan literacy. 


\section{REFERENCES}

Abaluck, J., and J. Gruber. (2011). "Choice Inconsistencies among the Elderly: Evidence from Plan Choice in the Medicare Part D Program." American Economic Review 101 (4): 1180-1210.

Akerlof, G.(1970). “The Market for 'Lemons’: Quality Uncertainty and the Market Mechanism.” The Quarterly Journal of Economics, 84 (3): 488-500.

Atanasov, P and T. Baker. (2014). "Putting Health Back Into Health Insurance Choice.” Medical Care Research and Review, 71(4): 337-355.

Baicker, K., Mullainathan, S., and J. Schwartzstein. (2013). “Behavioral Hazard in Health Insurance.” Working paper.

Baker, T. (2011). "Health Insurance, Risk, and Responsibility after the Patient Protection and Affordable Care Act.” University of Pennsylvania Law Review, 159: 1577.

Barseghyan, L., F. Molinari, T. O'Donoghue, and J. Teitelbaum. (2013). “The Nature of Risk Preferences: Evidence from Insurance Choices.” American Economic Review 103 (6): 2499-2529.

Barseghyan, L., F. Molinari, and J. Teitelbaum. (2014). “Inference under Stability of Risk Preferences.” Working paper

Bhargava, S., and G. Loewenstein. (2015). "Behavioral Economics and Policy 102: Beyond Nudging.” American Economic Review, Papers and Proceedings, Forthcoming.

Bhargava, S., and D. Manoli. (2014) "Why are Benefits Left on the Table? Assessing the Role of Information, Complexity, and Stigma on Take-up with an IRS Field Experiment.” Working Paper, University of Chicago.

Bhargava, S., Benartzi, S., and G. Loewenstein. (2014) "The ACA Exchanges and the Behavioral Economics of Choice.” mimeo, Carnegie Mellon University.

Burke, A., Misra, A., and S. Sheingold. (2014) "Premium Affordability, Competition, and Choice in the Health Insurance Marketplace, 2014.” ASPE Research Brief, Department of Health and Human Services.

Bordalo, P., N. Gennaioli, and A. Shleifer. (2012) "Salience Theory of Choice Under Risk.” Quarterly Journal of Economics, 127 (3): 1243-1285.

Choi, J., D. Laibson and B. Madrian. (2009). "Reducing the complexity costs of 401 (k) participation: the case of quick enrollment.” In: Wise, D.A. (Ed.), Developments in the Economics of Aging. University of Chicago Press, Chicago: 57-82. 
Congdon, J., Kling., J., and S. Mullainathan (2010). Policy and Choice: Public Finance through the Lens of Behavioral Economics, Washington, DC: Brookings Institution Press.

DellaVigna, S., and U. Malmendier. (2004). “Contract Design and Self-Control: Theory and Evidence.” The Quarterly Journal of Economics 119 (2): 353-402.

DellaVigna, S. (2009). "Psychology and Economics: Evidence from the Field.” Journal of Economic Literature 47(2): 315-72.

Einav, L. and A. Finkelstein. (2011). "Selection in Insurance Markets: Theory and Empirics in Pictures." Journal of Economic Prospects 25(1): 115-138.

Einav, L., Finkelstein, A., and M.R. Cullen. (2010). "Estimating Welfare in Insurance Markets using Variation in Prices.” Quarterly Journal of Economics 125(3): 877-921.

Einav, L., Finkelstein, A., and J. Levin. (2010). “Beyond Testing: Empirical Models of Insurance Markets.” Annual Review of Economics. 2: 311-336.

Einav, L., A. Finkelstein, S. Ryan, P. Schrimpf, and M. Cullen. (2013). “Selection on Moral Hazard in Health Insurance.” American Economic Review 103(1), 178-219.

Ericson, K. (forthcoming). "Consumer Intertia and Firm Pricing in the Medicare Part D Prescription Drug Insurance Exchange.” American Economic Journal: Economic Policy.

Ericson, K., and A. Starc, (2012). "Heuristics and Heterogeneity in Health Insurance Exchanges: Evidence from the Massachusetts Connector.” American Economic Review Papers and Proceedings 102(3): 493-497.

Eyster, E. and M. Rabin. (2005). “Cursed Equilibrium.” Econometrica 73(5): 1623-1672.

Fang, H., Keane, M. and D. Silverman, (2008). "Sources of Advantageous Selection: Evidence from the Medigap Insurance Market.” Journal of Political Economy, 116(2),303-350.

Frank, R.G., and K. Lamiraud. (2009). "Choice, Price Competition and Complexity in Markets for Health Insurance.” Journal of Economic Behavior and Organizaion, 71 (2), 550-562.

Gabaix, X., and D. Laibson. (2006). "Shrouded Attributes, Consumer Myopia, and Information Suppression in Competitive Markets.” The Quarterly Journal of Economics 121 (2): 505-540

Handel, B. (2013). “Adverse Selection and Inertia in Health Insurance Markets: When Nudging Hurts.” American Economic Review 103 (7): 2643-2682.

Handel, B. and J. Kolstad, (forthcoming). "Health Insurance for “Humans”: Information Frictions, Plan Choice, and Consumer Welfare,” American Economic Review.

Hastings, J., and J. Weinstein. (2008). "Information, school choice, and academic achievement: evidence from two experiments.” Quarterly Journal of Economics 123(4): 1373-1414.

Heidhues, P., and B. Kőszegi. (2014). “Using Information about Naivete to Price Discriminate.” mimeo, ESMT. 
Heiss, F., D. L. McFadden, and J. K. Winter. (2010). "Mind the Gap! Consumer Perceptions and Choices of Medicare Part D Prescription Drug Plans." David A. Wise (Ed.), Research Findings in the Economics of Aging, The University of Chicago Press, 413-481.

Ho, K., J. Hogan, and F.S. Morton. (2014). “The Impact of Consumer Inattention on Insurer Pricing in the Medicare Part D Program.” mimeo, Columbia University.

Johnson E., R. Hassin, T. Baker, A. Bajger, and G. Treuer. (2013). “Can Consumers Make Affordable Care Affordable? The Value of Choice Architecture.” PLoS ONE 8(12): e81521. doi:10.1371/journal.pone.0081521.

Kamenica, Emir. (2008). "Contextual Inference in Markets: On the Informational Content of Product Lines,” American Economic Review 98 (5): 2127-2149.

Ketcham, J., C. Lucarelli, E. Miravete, and C. Roebuck. (2012). "Sinking, Swimming, or Learning to Swim in Medicare Part D?." American Economic Review 102 (6): 2639-2673.

Kling, J., S. Mullainathan, E. Shafir, L. Vermeulen, and M. Wrobel. (2012). “Comparison Friction: Experimental Evidence from Medicare Drug Plans.” Quarterly Journal of Economics 127 (1): 199-235.

Kolstad, J. and A. Kowalski. (2012). "Mandate-Based Health Reform and the Labor Market: Evidence from The Massachusetts Reform," NBER Working Paper No. 17933.

Koszegi, B., and M. Rabin. (2007). "Reference-Dependent Risk Attitudes.” American Economic Review 97(4): 1047-73.

Liebman, J. and R. Zeckhauser (2008). “Simple Humans, Complex Insurance, Subtle Subsidies.” NBER Working Paper No. 14330.

Loewenstein, G., et al. (2013). “Consumers’ Misunderstanding of Health Insurance.” Journal of Health Economics 32(5): 850-862.

Prelec, D. and G. Loewenstein. (1998). “The Red and the Black: Mental Accounting of Savings and Debt.” Marketing Science 17(1): 4-28.

Prelec, D., B. Wernerfelt, and F. Zettelmeyer. (1997). "The Role of Inference in Context Effects: Inferring What You Want from What is Available.” Journal of Consumer Research 24(1): 118-125.

Rabin, M. (2000). “Risk Aversion and Expected-Utility Theory: A Calibration Theorem.” Econometrics 68(5): 1281-92.

Rothschild, M. and J. Stiglitz. (1976) "Equilibrium in Competitive Insurance Markets: An Essay on the Economics of Imperfect Information.” Quarterly Journal of Economics 90(4): 629-649. 
Sandroni, A., and F. Squintani. (2007). “Overconfidence, Insurance, and Paternalism.” American Economic Review 97 (5): 1994-2004.

Schram, A., and J. Sonnemans. (2011.) "How individuals choose health insurance: An experimental analysis.” European Economic Review 55(6): 799-819.

Schmitz, H. and N.R. Ziebarth. (2015) "Does price framing affect the consumer price sensitivity of health plan choice?” Working paper.

Spinewijn, J. (2014). “Heterogeneity, Demand for Insurance and Adverse Selection.” Working paper.

Strombom, B., T. Buchmueller, and P. Feldstein. (2002). "Switching costs, price sensitive and health plan choice.” Journal of Health Economics, 21(1): 89-116.

Sydnor, J. (2010). “(Over)insuring Modest Risks.” American Economic Journal: Applied Economics 2(4): 177-199.

Thaler, R. and C. Sunstein. (2008). Nudge: Improving Decisions about Health, Wealth, and Happiness. Yale University Press.

Winter, J., R. Balza, F. Caro, F. Heiss, B. Jun, R. Matzkin, and D. McFadden. (2006). "Medicare prescription drug coverage: consumer information and preference.” Proceedings of the National Academy of Sciences 103(20): 7929-7934.

Zhou, C., and Y. Zhang. (2012). “The Vast Majority of Medicare Part D Beneficiaries Still Don’t Choose the Cheapest Plans That Meet Their Medication Needs.” Health Affairs 31(10): 2259-65. 


\section{TABLES AND FIGURES}

Figure 1. Total Employee Spending (Premium + Out of Pocket) by Medical Expenses (Premium for \$1,000 Deductible Option Normed at \$0)

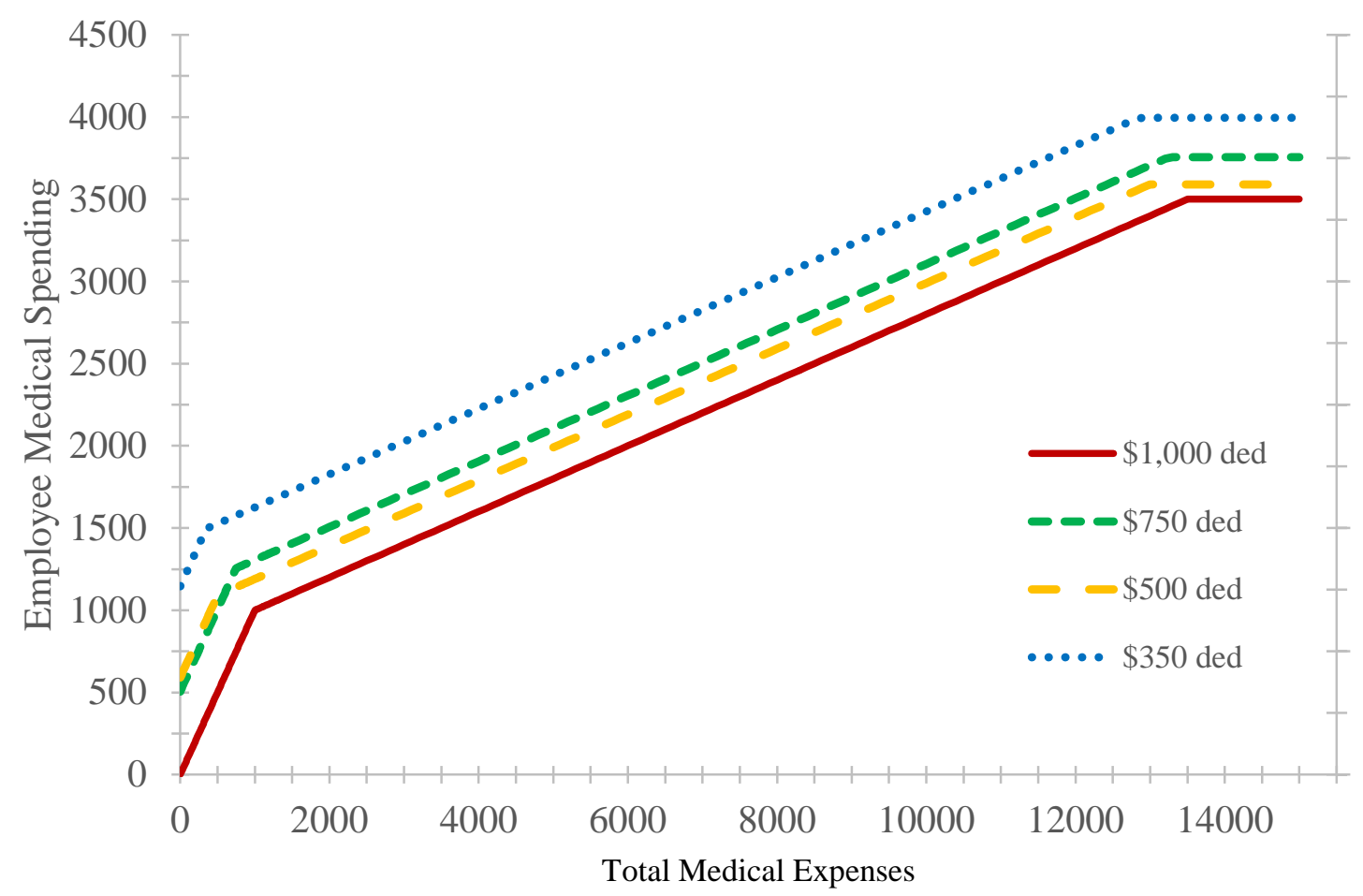

Notes: This figure shows the schedule of employee spending as a function of total medical expenses by deductible levels for contracts with $\$ 2,500$ out-of-pocket max (above the deductible), 80\% coinsurance above the deductible and \$25/\$35 copayments (which did not count against deductible or out-of-pocket max). Employee spending includes both the out-of-pocket medical expenditures and premium expenses. To facilitate comparison we norm the annual employee premium for the $\$ 1,000$ deductible contract to zero such that the point where the schedules for the other deductible options intersect the $y$-axis reflects the additional yearly premium charge for those plans relative to the $\$ 1,000$ deductible option. 


\title{
Figure 2. Employee Plan Choice
}

\author{
A. Distribution of Deductible Choice
}

$50 \%$

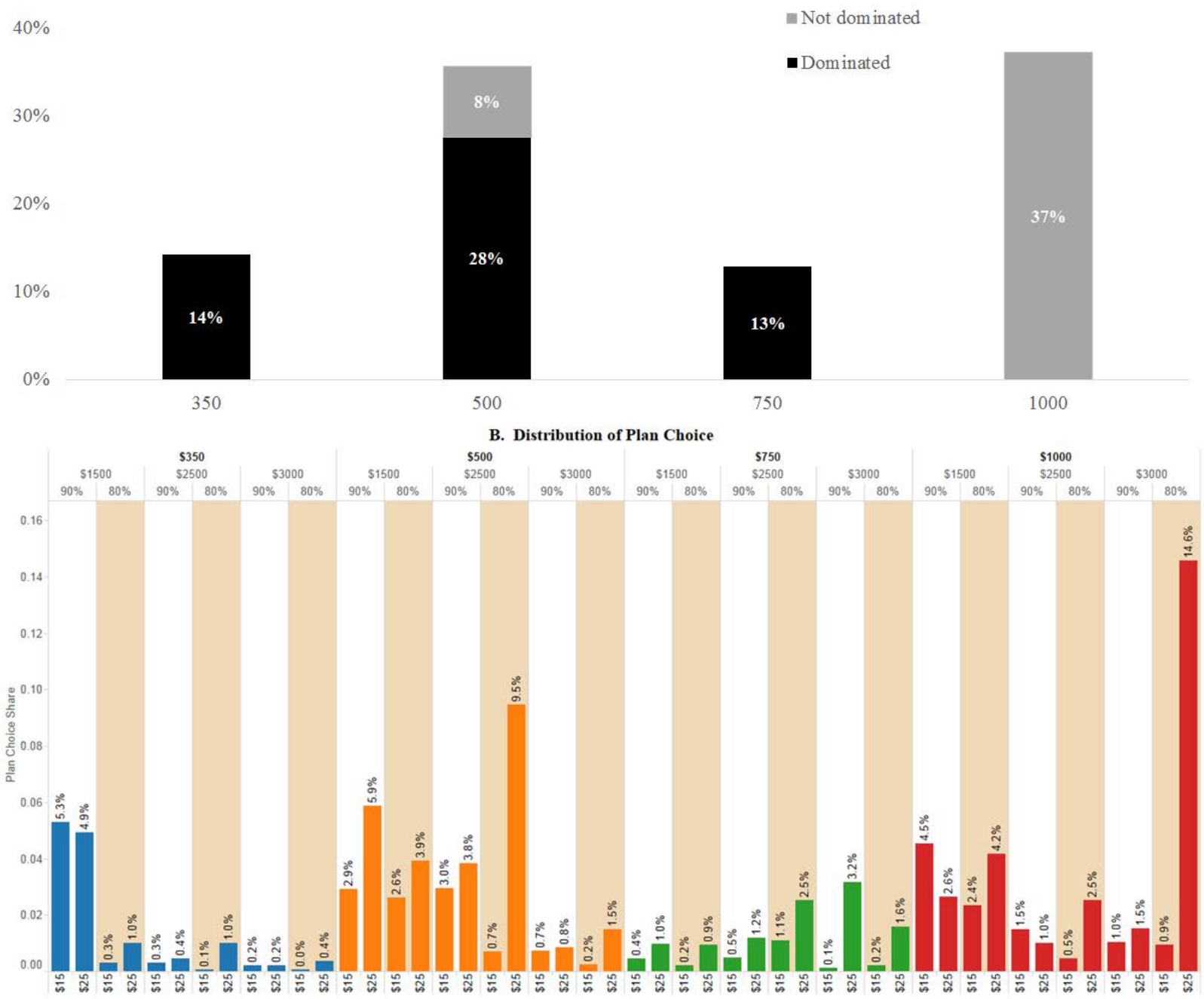

Notes: In Panel A, plan domination reflects instances in which the difference in tax-adjusted price (adjusted by the marginal tax rate implied by each employee's salary band) between the chosen plan and the equivalent plan with the $\$ 1,000$ deductible exceeds the difference in deductibles between the plans. 
Figure 3. Distribution of Savings Associated with Counterfactual Plan Choice (by current plan deductible)

Panel A. Switch to equivalent plan with the $\$ 1,000$ deductible

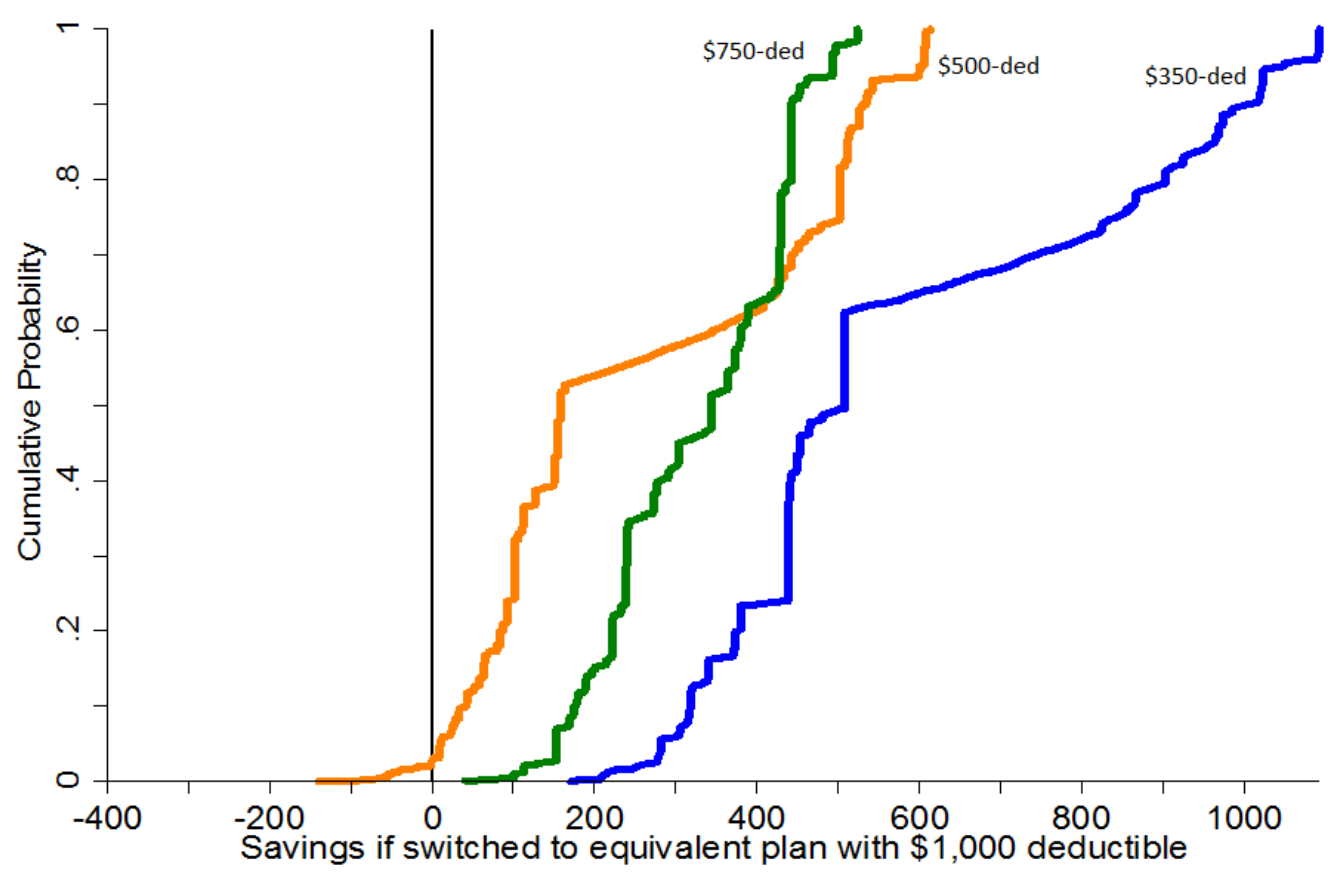

Panel B. Switch to actuarial-low-cost plan 41

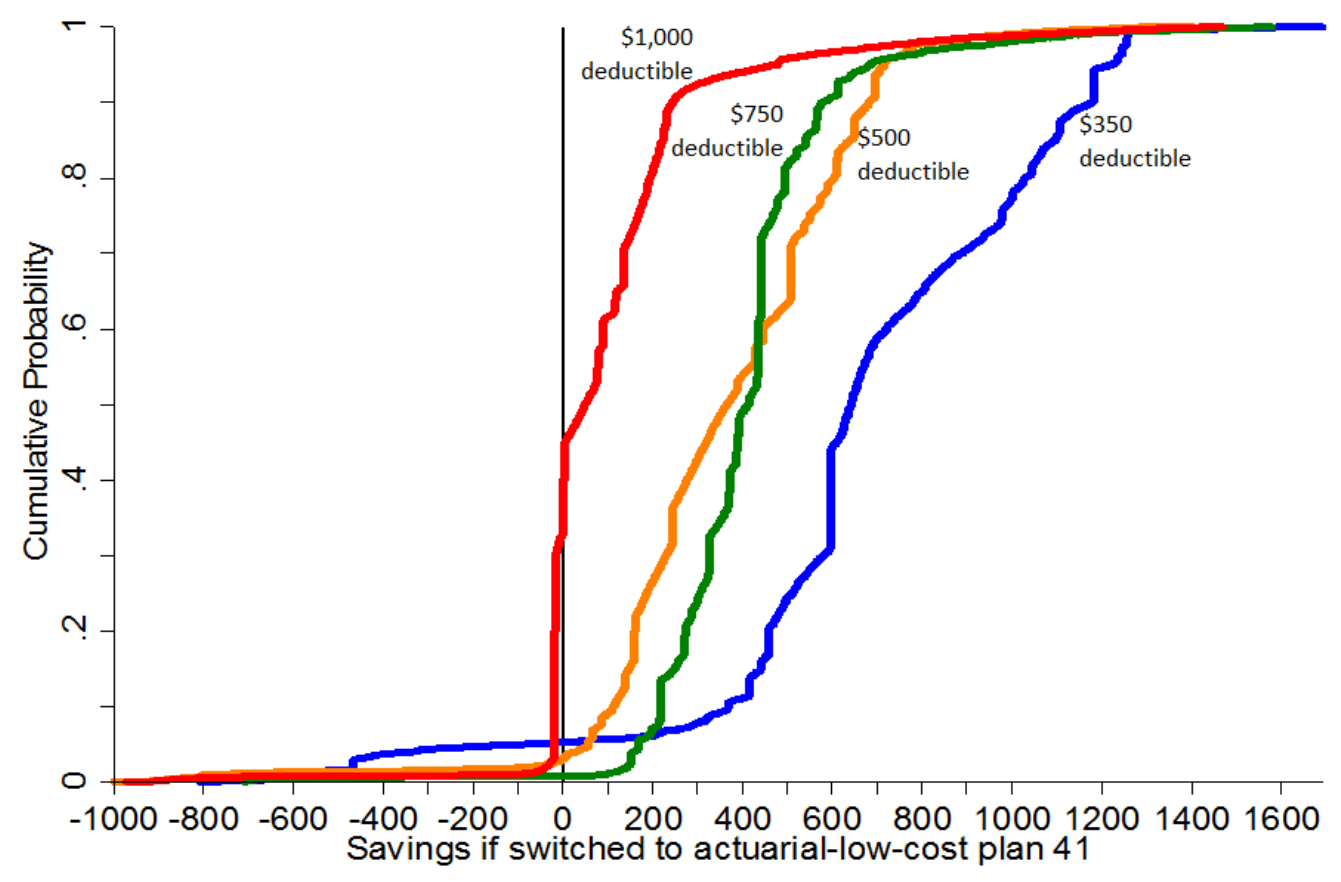

Note: These plots shows the cumulative distribution of potential counterfactual after-tax savings if the employees who chose a plan with the indicated deductible had instead switched to the alternative specified in the Panel. The counterfactual savings are calculated as the individuals tax-adjusted premium savings (calculated using the federal marginal tax rate implied by the employee's salary range) less the increase in out-of-pocket spending for health care the individual would have experienced with the switch given the individual's observed health spending under the chosen plan. 
Panel A. Fraction Selecting a Plan Dominated by Equivalent Plan with \$1,000 Deductible

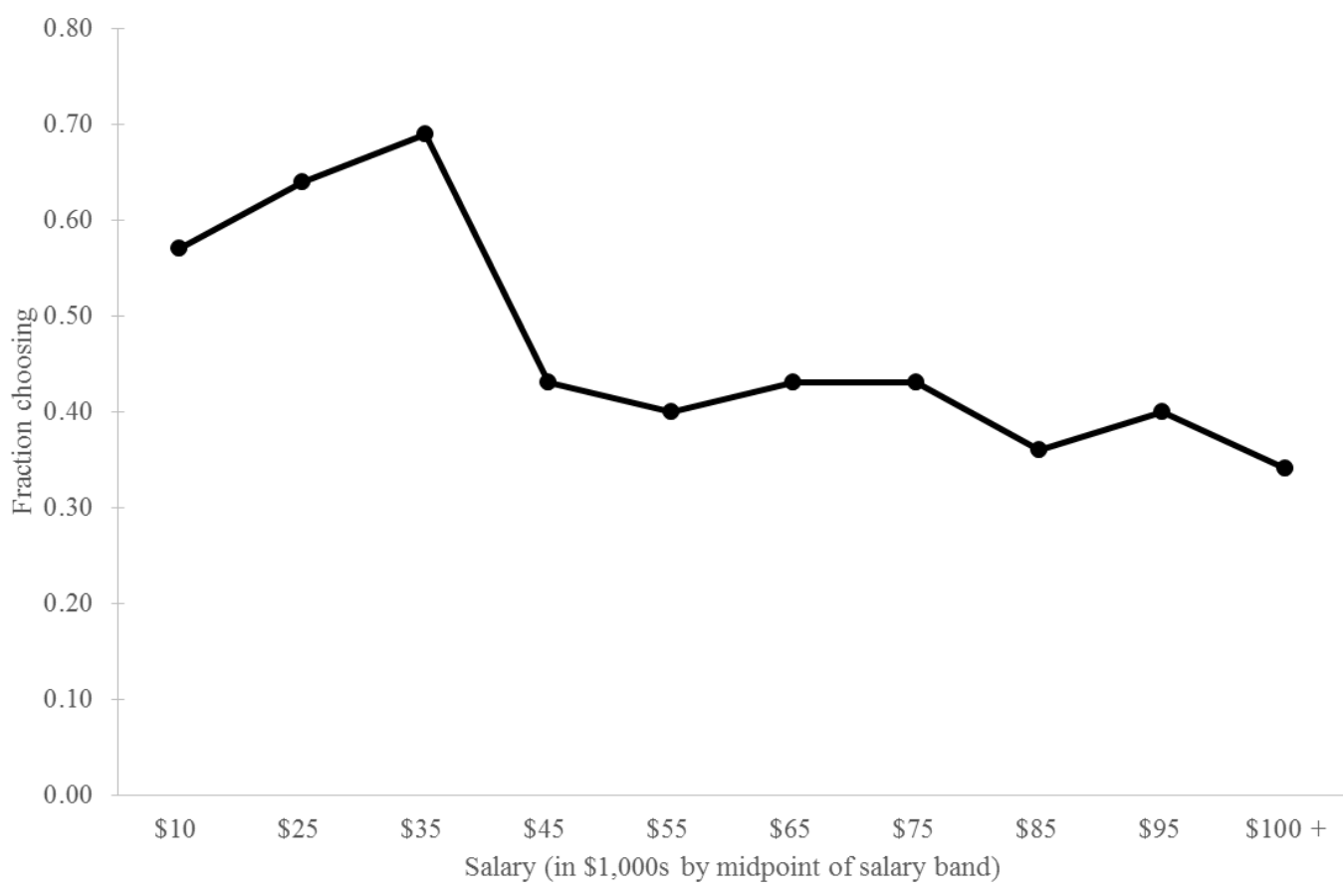

Panel B. Average Counterfactual Savings with Switch to Actuarial-low-cost Plan 41

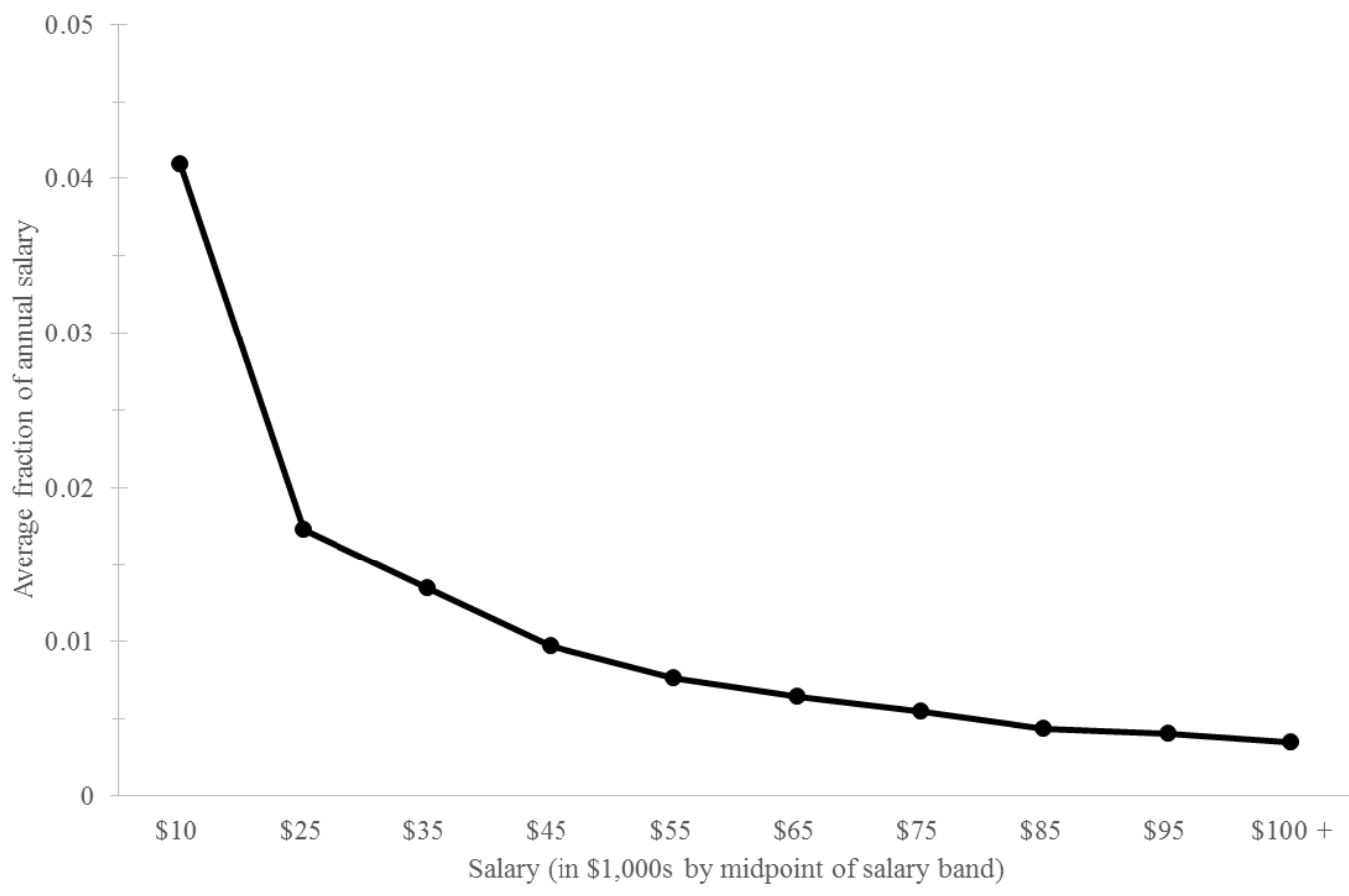

Notes: Panel A shows the fraction of employees at each salary band who chose a plan with a lower deductible that was dominated by the equivalent plan with the $\$ 1,000$-deductible alternative after adjusting the premium costs to reflect the individual employee's federal marginal tax rate implied by the salary band. Panel B shows the average counterfactual savings across all employees in the salary band as a fraction of annual salary if all the employees had instead had the actuarial-low-cost plan 41 . This counterfactual is calculated across all employees, including those who did not choose a dominated deductible and those who were already in plan 41 (for whom the counterfactual savings is $\$ 0$ by construction) 
Figure 5. Propensity to Change Plans and PY 2011 Destination

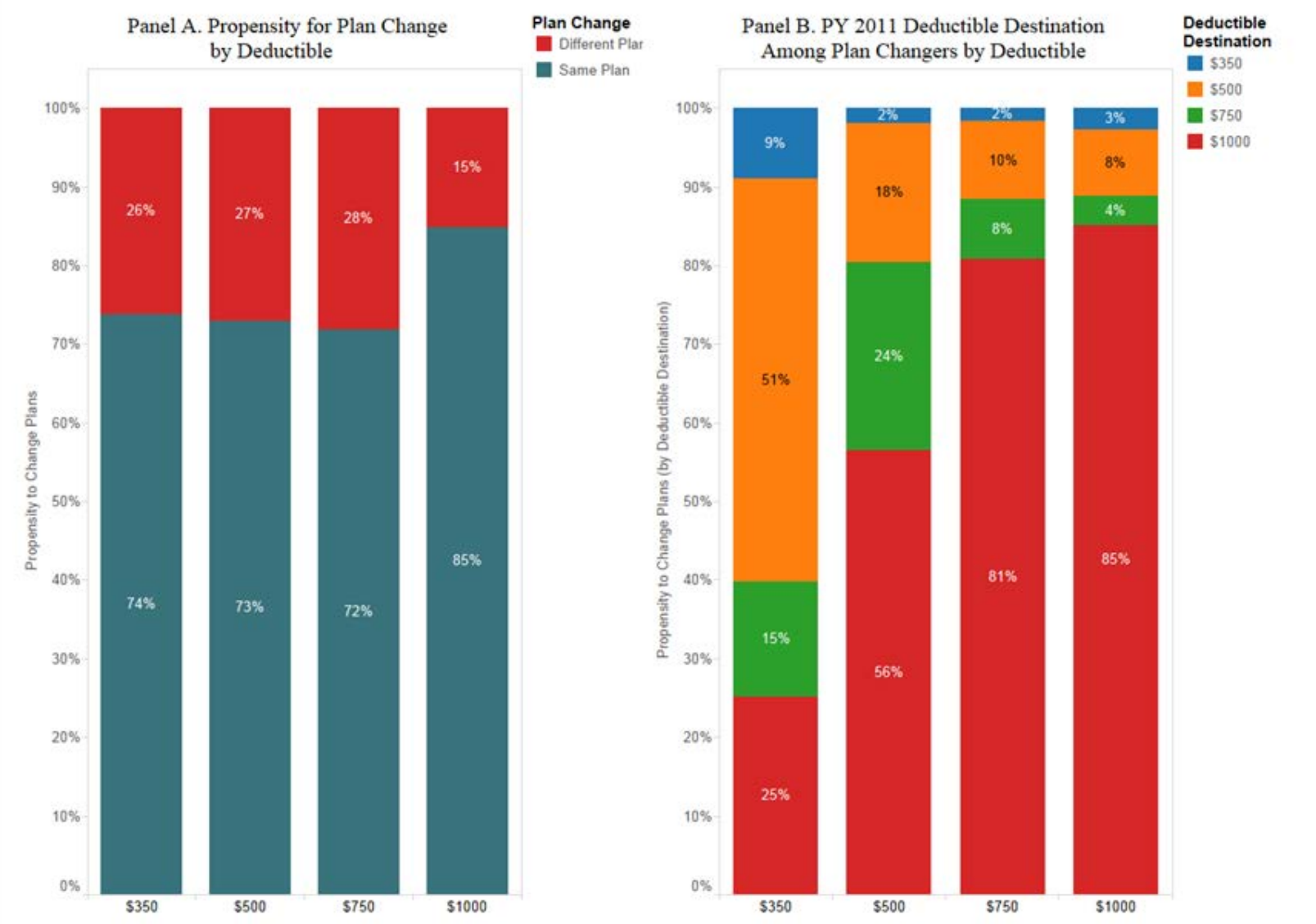

Notes: The figure summarizes the employee propensity to change health plans for PY2011 as well plan destination by chosen deductible. The figure is restricted to the set of employees with single coverage included in the primary analysis and who also did not exit the firm in PY2011. Panel A describes plan change behavior by PY 2010 deductible, and Panel B describes the distribution of new plan deductibles by prior year deductible for those who changed their plan. Note that employees can change plans both within and across deductible levels. Plan menu was unchanged from PY 2010 to PY 2010 apart from small changes to plan premiums. 
Figure 6. Menu Complexity and Choice Quality (Experiment 1)
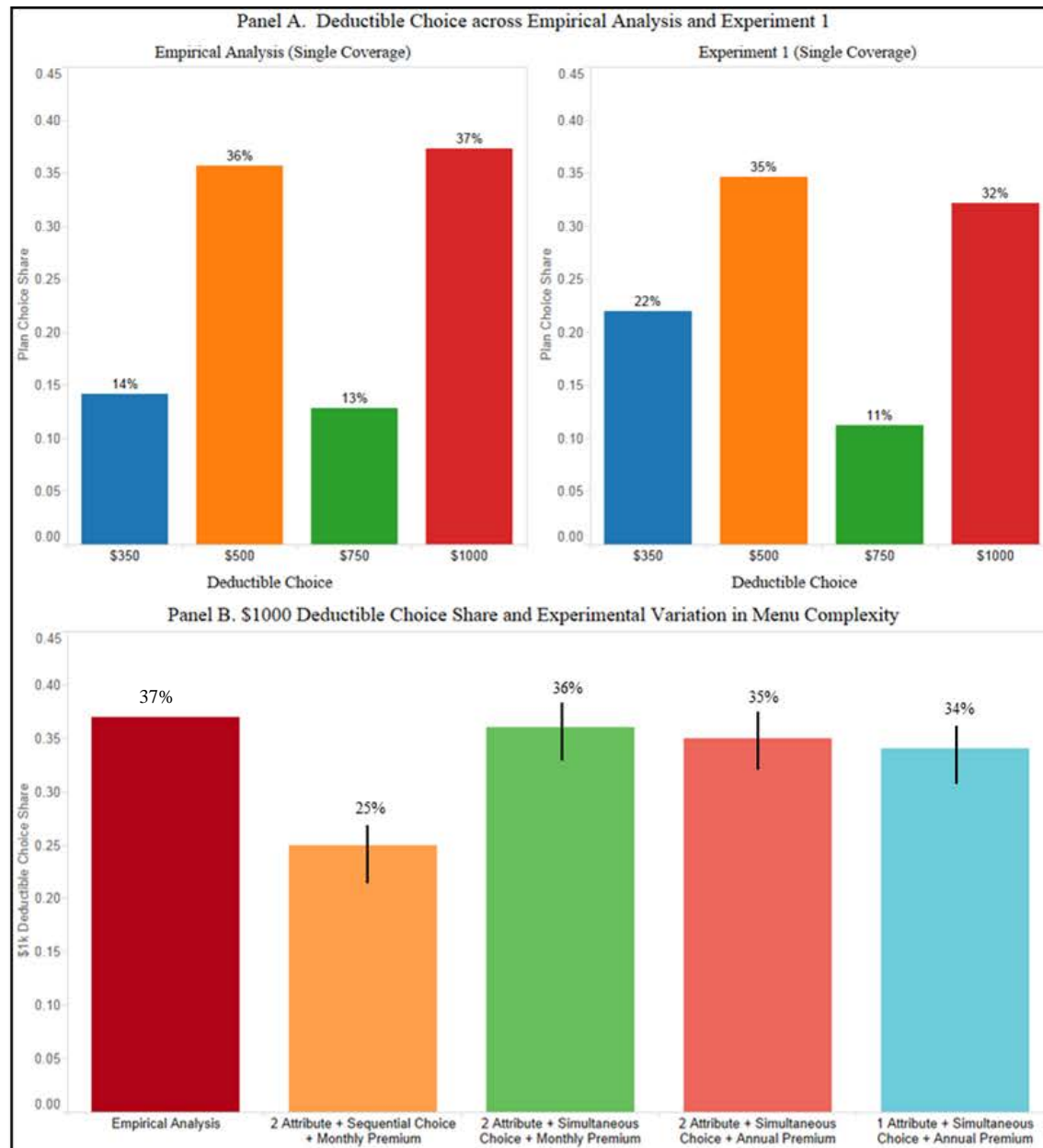

Panel C. Simplification and Improvement of Choice by Income

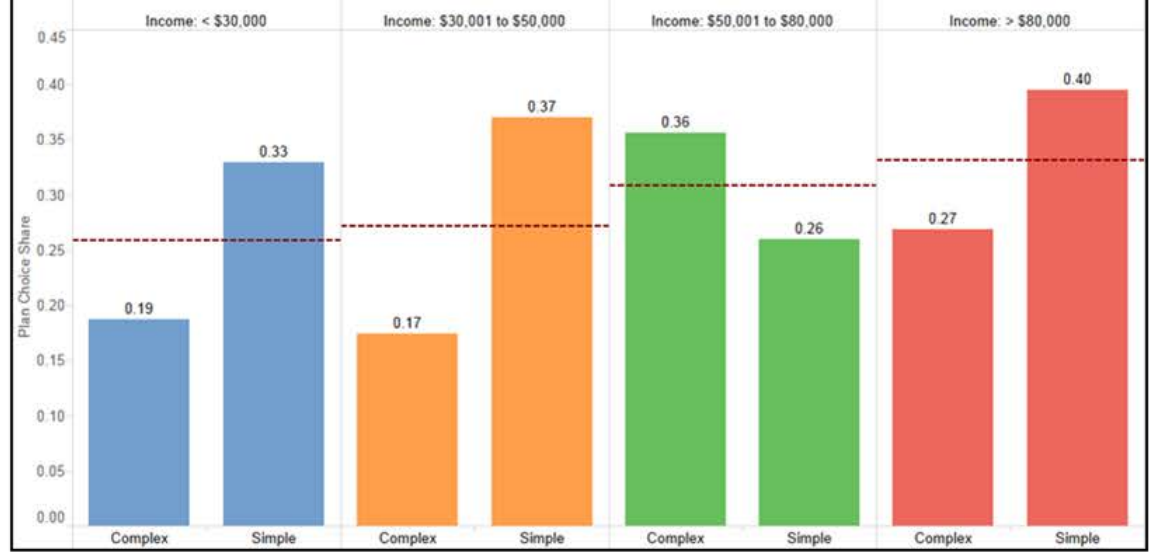

Notes: Panel A compares the distribution of deductible choice of firm employees from the main empirical analysis to the analogous distribution of deductible choice for participants in Experiment 1 (across all conditions). Panel B compares the share of $\$ 1,000$ deductible choice from the empirical analysis and a range of experimental conditions which vary the complexity of plan menus and the difficulty of search. Bars indicate $+1 /-1$ standard errors. Panel $\mathrm{C}$ reports choice quality for the highly complex (i.e., 2 Attribute + Sequential Choice + Monthly Premium) and highly simple menus (1 Attribute + Simultaneous Choice + Annual Premium) by income category. 
Figure 7. Health Insurance Literacy, Search Motivation and Choice Quality (Experiment 2)

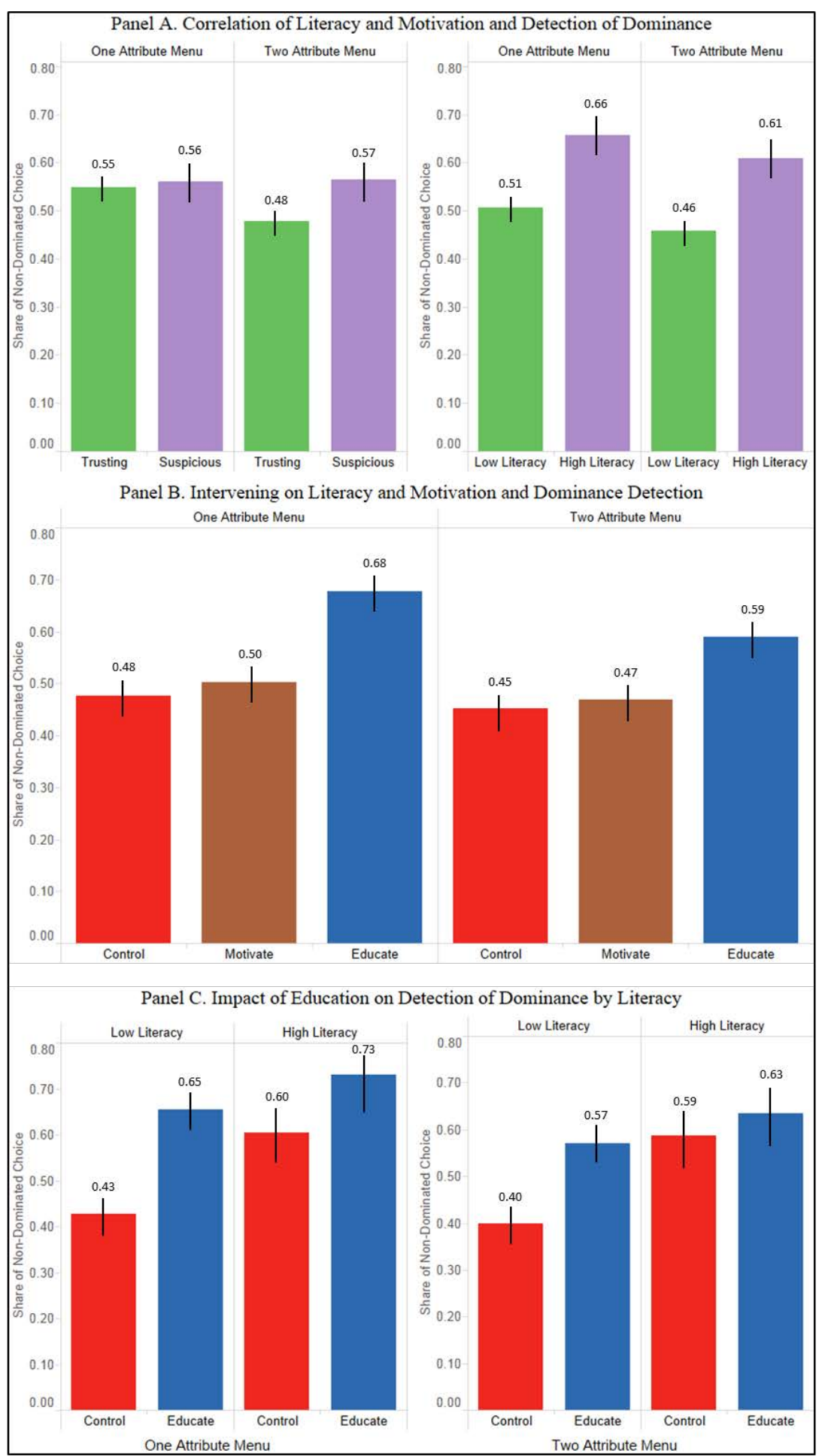

Notes: Panel A documents the correlation between health literacy, beliefs regarding the likelihood of encountering financially unattractive plans, and plan choice quality for both the one and two attribute choice conditions (across all conditions). "Trusting" includes participants who indicated that they were unsure of their beliefs (18\% of sample). Panel B documents plan choice quality across the three experimental conditions (control, motivation, and education conditions). Panel $\mathrm{C}$ reports choice quality for the control and education conditions for low and high literacy groups. Bars indicate $+1 /-1$ standard error intervals. 
Figure 8. Responsiveness of Demand to Plan Price and Perceived Health Status (Experiment 3)

Panel A. Fraction Choosing \$1k Deductible by Randomized Premium Differentials

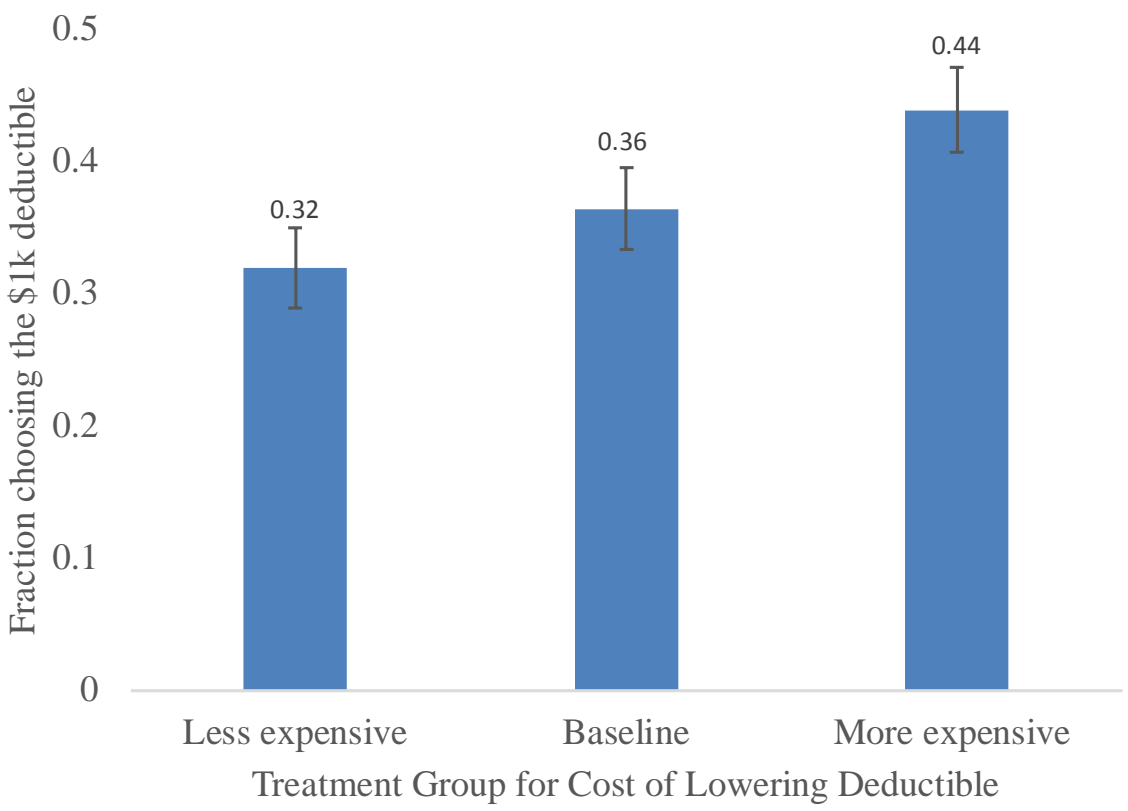

Panel B. Fraction Choosing \$1k Deductible by Self-Perceived Health Status

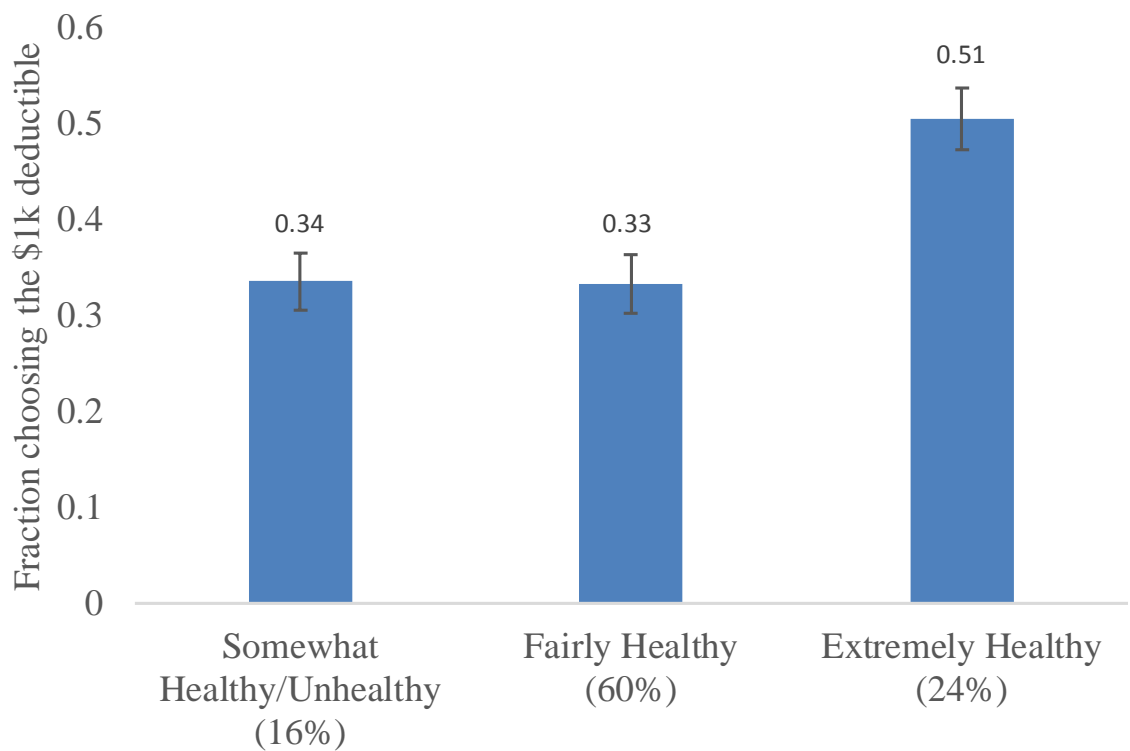

Self-reported Health Status

Notes: Panel A shows the fraction of subjects choosing the $\$ 1,000$ deductible for each of the treatment groups in the experiment. The baseline pricing matches the price levels for Plans 46, 34, 22, and 10 (listed in Table 1). The less expensive treatment lowers the price differentials between lower deductibles and the $\$ 1,000$-deductible option by $25 \%$, while the more expensive treatment increases the price differentials by $25 \%$. Panel B shows the correlation of choice with self-reported health status. The percent of subjects reporting each health-status level is given in parenthes. Bars indicate $+1 /-1$ standard error intervals. 
Figure 9. Employee Premium Relative to Medical Spending across Plan Features

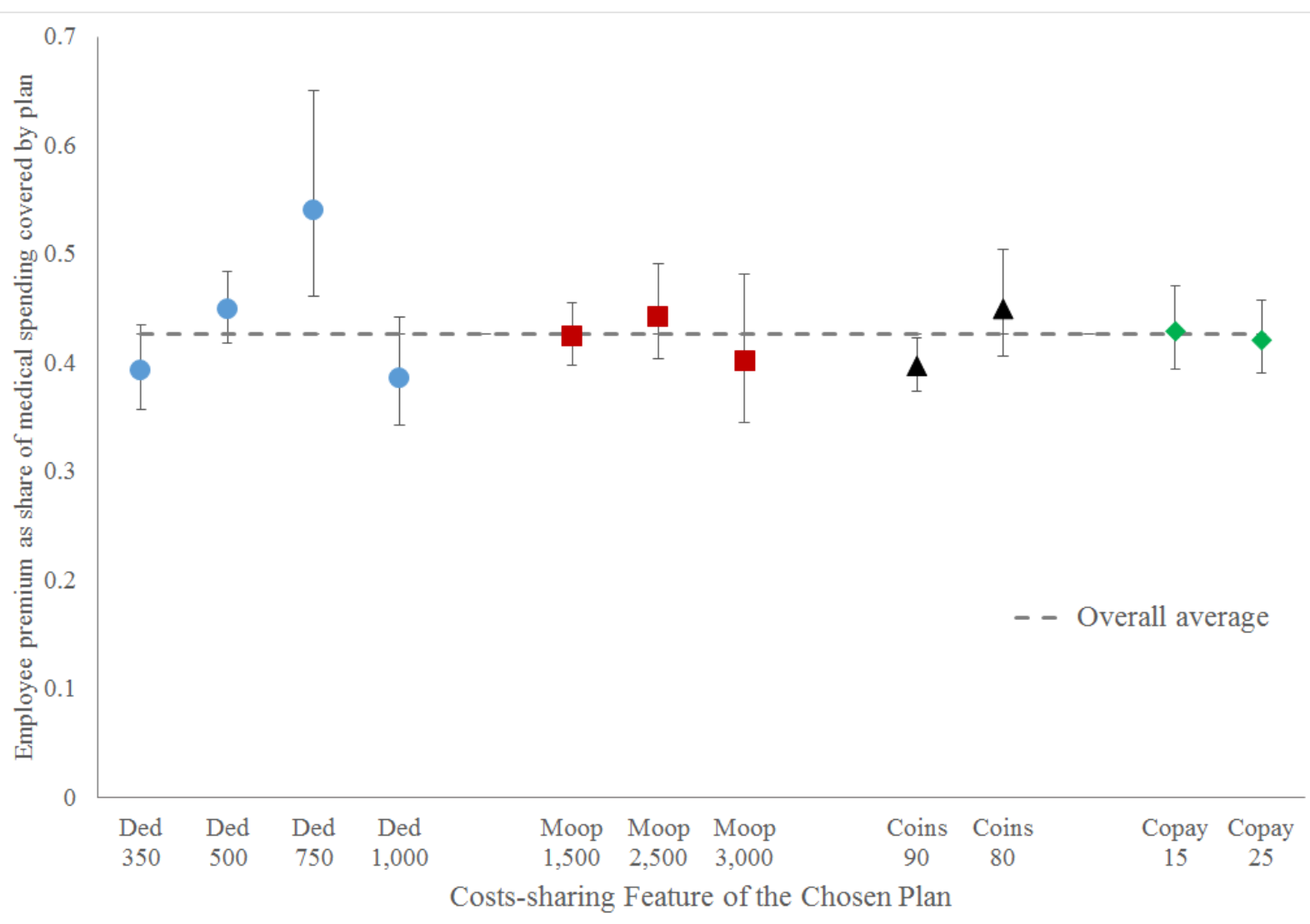

Note: This figure shows the average ratio of an employee's paid premium to the total spending for the employee's health-care incrurred by the plan (i.e., paid by the employer). Each dot averages across individuals who chose plans with that cost-sharing feature. $95 \%$ confidence intervals on the ratio are given by the error bars. 


\section{Figure 10. Illustrative Welfare Analysis from Simulations}

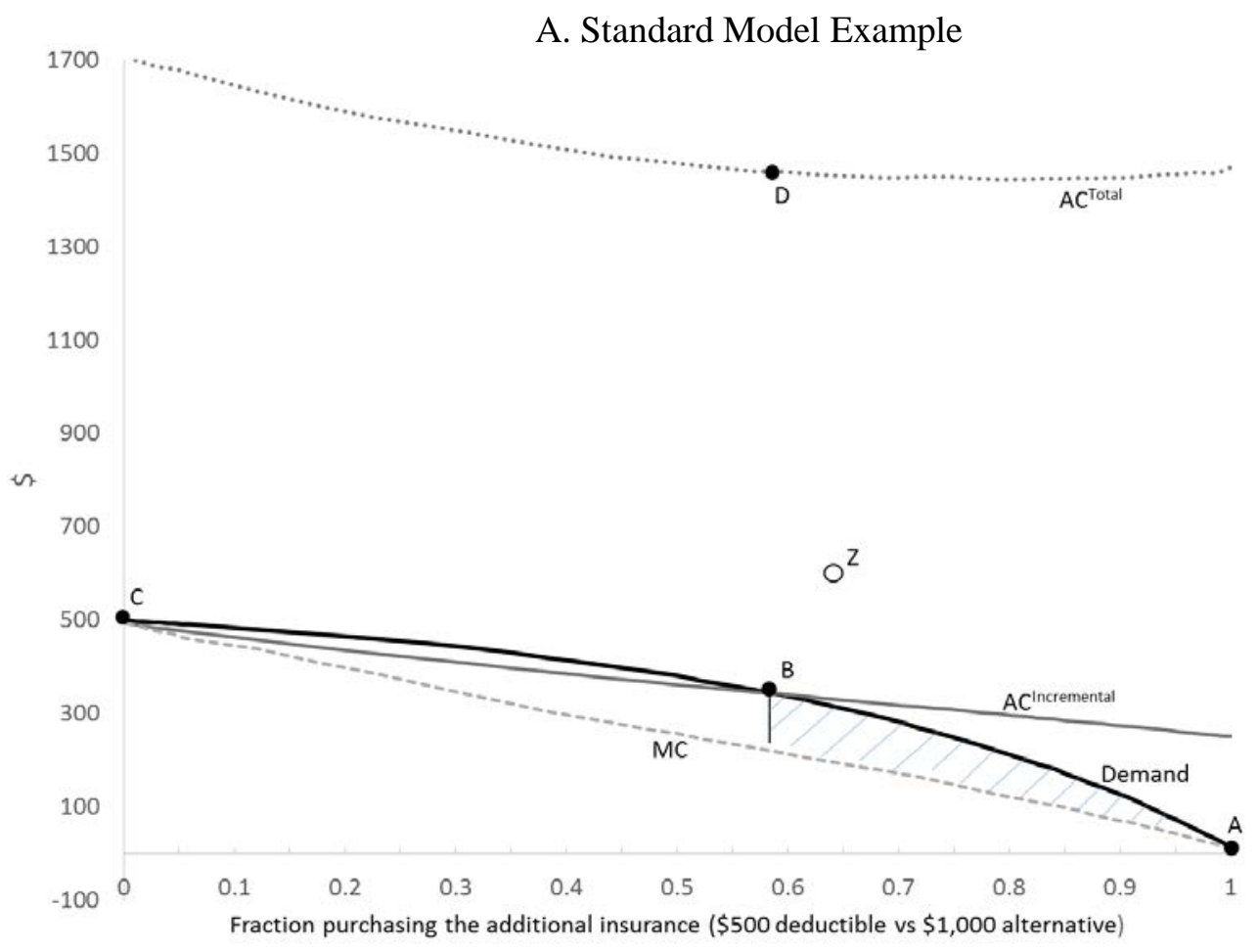

B. Heuristic-Choice Example

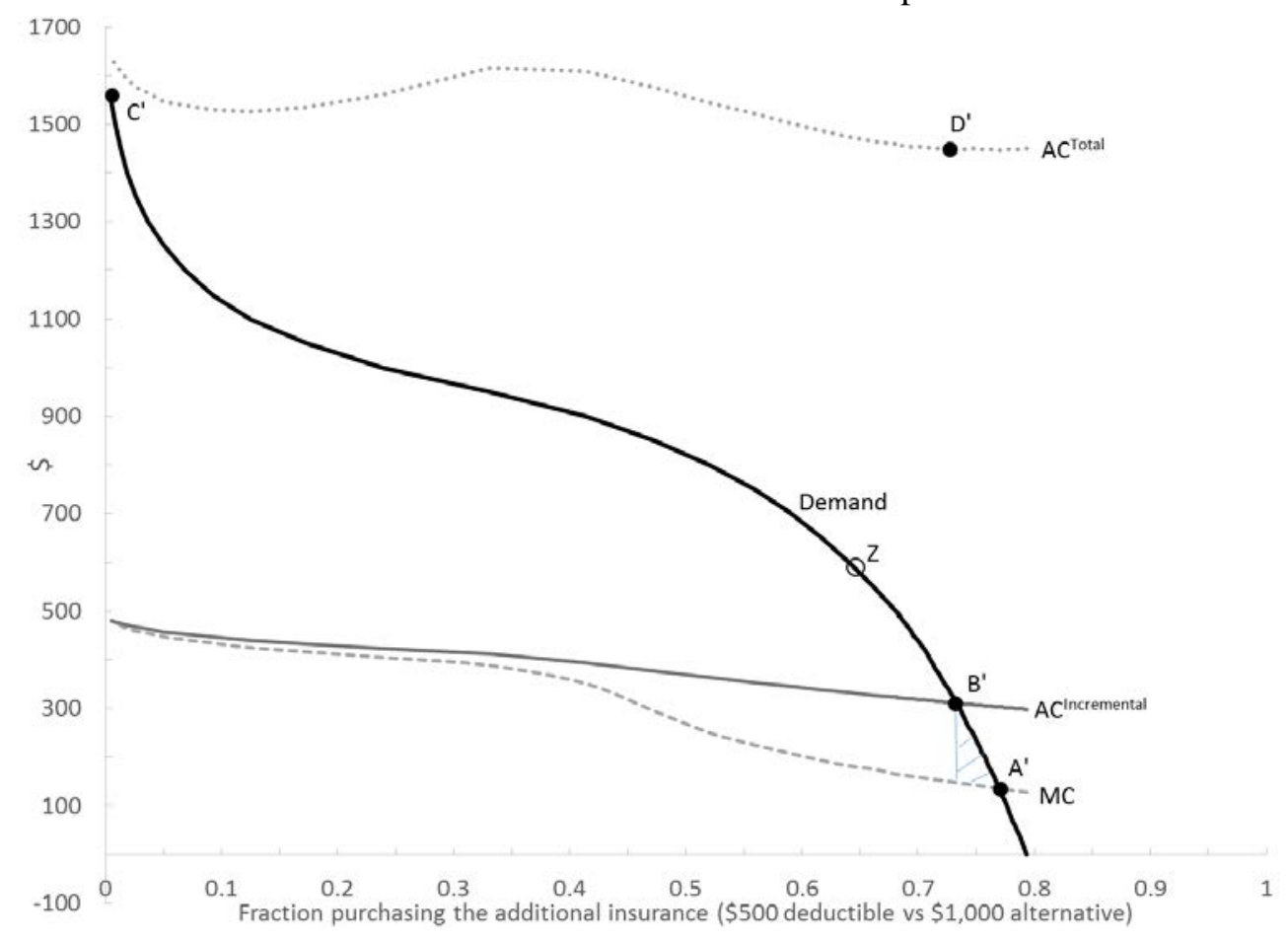

Notes: See Section 6 for a description of the simulation parameters used to generate these examples. 
Table 1

PLAN MENU DETAILS \& PRICE DOMINATION

\begin{tabular}{|c|c|c|c|c|c|c|c|c|}
\hline Plan Name & Deductible & Coinsurance & $\begin{array}{c}\text { Out-of-Pocket } \\
\text { Max }\end{array}$ & Office Copayment & Choice Share & Premium & $\begin{array}{c}\text { Cost Difference Relative to } \$ 1 \mathrm{~K} \\
\text { Deductible Plan }\end{array}$ & $\begin{array}{l}\text { Tax Adjusted Cost Difference } \\
\text { Relative to \$1K Deductible Plan }\end{array}$ \\
\hline Plan 1 & $\$ 350$ & $90 \%$ & $\$ 1,500$ & $\$ 15 / \$ 40$ & $5.3 \%$ & $\$ 2,134$ & $\$ 1,204$ & $\$ 975$ \\
\hline Plan 2 & $\$ 350$ & $90 \%$ & $\$ 2,500$ & $\$ 15 / \$ 40$ & $0.3 \%$ & $\$ 1,983$ & $\$ 1,235$ & $\$ 1,000$ \\
\hline Plan 3 & $\$ 350$ & $90 \%$ & $\$ 3,000$ & $\$ 15 / \$ 40$ & $0.2 \%$ & $\$ 1,912$ & $\$ 1,255$ & $\$ 1,017$ \\
\hline Plan 4 & $\$ 350$ & $90 \%$ & $\$ 1,500$ & $\$ 25 / \$ 35$ & $4.9 \%$ & $\$ 2,047$ & $\$ 1,286$ & $\$ 1,042$ \\
\hline Plan 5 & $\$ 350$ & $90 \%$ & $\$ 2,500$ & $\$ 25 / \$ 35$ & $0.4 \%$ & $\$ 1,862$ & $\$ 1,206$ & $\$ 977$ \\
\hline Plan 6 & $\$ 350$ & $90 \%$ & $\$ 3,000$ & $\$ 25 / \$ 35$ & $0.2 \%$ & $\$ 1,778$ & $\$ 1,124$ & $\$ 910$ \\
\hline Plan 7 & $\$ 350$ & $80 \%$ & $\$ 1,500$ & $\$ 15 / \$ 40$ & $0.3 \%$ & $\$ 2,037$ & $\$ 1,160$ & $\$ 940$ \\
\hline Plan 8 & $\$ 350$ & $80 \%$ & $\$ 2,500$ & $\$ 15 / \$ 40$ & $0.1 \%$ & $\$ 1,889$ & $\$ 1,176$ & $\$ 952$ \\
\hline Plan 9 & $\$ 350$ & $80 \%$ & $\$ 3,000$ & $\$ 15 / \$ 40$ & $0.1 \%$ & $\$ 1,608$ & $\$ 967$ & $\$ 783$ \\
\hline Plan 10 & $\$ 350$ & $80 \%$ & $\$ 1,500$ & $\$ 25 / \$ 35$ & $1.0 \%$ & $\$ 1,957$ & $\$ 1,140$ & $\$ 924$ \\
\hline Plan 11 & $\$ 350$ & $80 \%$ & $\$ 2,500$ & $\$ 25 / \$ 35$ & $1.0 \%$ & $\$ 1,808$ & $\$ 1,146$ & $\$ 928$ \\
\hline Plan 12 & $\$ 350$ & $80 \%$ & $\$ 3,000$ & $\$ 25 / \$ 35$ & $0.4 \%$ & $\$ 1,605$ & $\$ 971$ & $\$ 786$ \\
\hline Plan 13 & $\$ 500$ & $90 \%$ & $\$ 1,500$ & $\$ 15 / \$ 40$ & $2.9 \%$ & $\$ 1,568$ & $\$ 638$ & $\$ 517$ \\
\hline Plan 14 & $\$ 500$ & $90 \%$ & $\$ 2,500$ & $\$ 15 / \$ 40$ & $3.0 \%$ & $\$ 1,455$ & $\$ 707$ & $\$ 572$ \\
\hline Plan 15 & $\$ 500$ & $90 \%$ & $\$ 3,000$ & $\$ 15 / \$ 40$ & $0.7 \%$ & $\$ 1,378$ & $\$ 722$ & $\$ 585$ \\
\hline Plan 16 & $\$ 500$ & $90 \%$ & $\$ 1,500$ & $\$ 25 / \$ 35$ & $5.9 \%$ & $\$ 1,474$ & $\$ 713$ & $\$ 577$ \\
\hline Plan 17 & $\$ 500$ & $90 \%$ & $\$ 2,500$ & $\$ 25 / \$ 35$ & $3.8 \%$ & $\$ 1,372$ & $\$ 716$ & $\$ 580$ \\
\hline Plan 18 & $\$ 500$ & $90 \%$ & $\$ 3,000$ & $\$ 25 / \$ 35$ & $0.8 \%$ & $\$ 1,252$ & $\$ 598$ & $\$ 484$ \\
\hline Plan 19 & $\$ 500$ & $80 \%$ & $\$ 1,500$ & $\$ 15 / \$ 40$ & $2.6 \%$ & $\$ 1,497$ & $\$ 620$ & $\$ 502$ \\
\hline Plan 20 & $\$ 500$ & $80 \%$ & $\$ 2,500$ & $\$ 15 / \$ 40$ & $0.7 \%$ & $\$ 1,315$ & $\$ 602$ & $\$ 487$ \\
\hline Plan 21 & $\$ 500$ & $80 \%$ & $\$ 3,000$ & $\$ 15 / \$ 40$ & $0.2 \%$ & $\$ 1,152$ & $\$ 511$ & $\$ 414$ \\
\hline Plan 22 & $\$ 500$ & $80 \%$ & $\$ 1,500$ & $\$ 25 / \$ 35$ & $3.9 \%$ & $\$ 1,419$ & $\$ 602$ & $\$ 488$ \\
\hline Plan 23 & $\$ 500$ & $80 \%$ & $\$ 2,500$ & $\$ 25 / \$ 35$ & $9.5 \%$ & $\$ 1,252$ & $\$ 590$ & $\$ 478$ \\
\hline Plan 24 & $\$ 500$ & $80 \%$ & $\$ 3,000$ & $\$ 25 / \$ 35$ & $1.5 \%$ & $\$ 1,114$ & $\$ 480$ & $\$ 389$ \\
\hline Plan 25 & $\$ 750$ & $90 \%$ & $\$ 1,500$ & $\$ 15 / \$ 40$ & $0.4 \%$ & $\$ 1,463$ & $\$ 533$ & $\$ 432$ \\
\hline Plan 26 & $\$ 750$ & $90 \%$ & $\$ 2,500$ & $\$ 15 / \$ 40$ & $0.5 \%$ & $\$ 1,333$ & $\$ 585$ & $\$ 474$ \\
\hline Plan 27 & $\$ 750$ & $90 \%$ & $\$ 3,000$ & $\$ 15 / \$ 40$ & $0.1 \%$ & $\$ 1,260$ & $\$ 603$ & $\$ 489$ \\
\hline Plan 28 & $\$ 750$ & $90 \%$ & $\$ 1,500$ & $\$ 25 / \$ 35$ & $1.0 \%$ & $\$ 1,377$ & $\$ 616$ & $\$ 499$ \\
\hline Plan 29 & $\$ 750$ & $90 \%$ & $\$ 2,500$ & $\$ 25 / \$ 35$ & $1.2 \%$ & $\$ 1,235$ & $\$ 579$ & $\$ 469$ \\
\hline Plan 30 & $\$ 750$ & $90 \%$ & $\$ 3,000$ & $\$ 25 / \$ 35$ & $3.2 \%$ & $\$ 1,173$ & $\$ 519$ & $\$ 421$ \\
\hline Plan 31 & $\$ 750$ & $80 \%$ & $\$ 1,500$ & $\$ 15 / \$ 40$ & $0.2 \%$ & $\$ 1,408$ & $\$ 531$ & $\$ 430$ \\
\hline Plan 32 & $\$ 750$ & $80 \%$ & $\$ 2,500$ & $\$ 15 / \$ 40$ & $1.1 \%$ & $\$ 1,217$ & $\$ 505$ & $\$ 409$ \\
\hline Plan 33 & $\$ 750$ & $80 \%$ & $\$ 3,000$ & $\$ 15 / \$ 40$ & $0.2 \%$ & $\$ 1,089$ & $\$ 448$ & $\$ 363$ \\
\hline Plan 34 & $\$ 750$ & $80 \%$ & $\$ 1,500$ & $\$ 25 / \$ 35$ & $0.9 \%$ & $\$ 1,321$ & $\$ 504$ & $\$ 408$ \\
\hline Plan 35 & $\$ 750$ & $80 \%$ & $\$ 2,500$ & $\$ 25 / \$ 35$ & $2.5 \%$ & $\$ 1,168$ & $\$ 506$ & $\$ 410$ \\
\hline Plan 36 & $\$ 750$ & $80 \%$ & $\$ 3,000$ & $\$ 25 / \$ 35$ & $1.6 \%$ & $\$ 1,038$ & $\$ 404$ & $\$ 327$ \\
\hline Plan 37 & $\$ 1,000$ & $90 \%$ & $\$ 1,500$ & $\$ 15 / \$ 40$ & $4.5 \%$ & $\$ 930$ & -- & - \\
\hline Plan 38 & $\$ 1,000$ & $90 \%$ & $\$ 2,500$ & $\$ 15 / \$ 40$ & $1.5 \%$ & $\$ 748$ & - & - \\
\hline Plan 39 & $\$ 1,000$ & $90 \%$ & $\$ 3,000$ & $\$ 15 / \$ 40$ & $1.0 \%$ & $\$ 657$ & -- & -- \\
\hline Plan 40 & $\$ 1,000$ & $90 \%$ & $\$ 1,500$ & $\$ 25 / \$ 35$ & $2.7 \%$ & $\$ 761$ & -- & -- \\
\hline Plan 41 & $\$ 1,000$ & $90 \%$ & $\$ 2,500$ & $\$ 25 / \$ 35$ & $1.0 \%$ & $\$ 656$ & -- & -- \\
\hline Plan 42 & $\$ 1,000$ & $90 \%$ & $\$ 3,000$ & $\$ 25 / \$ 35$ & $1.5 \%$ & $\$ 654$ & -- & -- \\
\hline Plan 43 & $\$ 1,000$ & $80 \%$ & $\$ 1,500$ & $\$ 15 / \$ 40$ & $2.4 \%$ & $\$ 877$ & -- & -- \\
\hline Plan 44 & $\$ 1,000$ & $80 \%$ & $\$ 2,500$ & $\$ 15 / \$ 40$ & $0.5 \%$ & $\$ 713$ & -- & - \\
\hline Plan 45 & $\$ 1,000$ & $80 \%$ & $\$ 3,000$ & $\$ 15 / \$ 40$ & $0.9 \%$ & $\$ 641$ & -- & -- \\
\hline Plan 46 & $\$ 1,000$ & $80 \%$ & $\$ 1,500$ & $\$ 25 / \$ 35$ & $4.2 \%$ & $\$ 817$ & -- & -- \\
\hline Plan 47 & $\$ 1,000$ & $80 \%$ & $\$ 2,500$ & $\$ 25 / \$ 35$ & $2.5 \%$ & $\$ 662$ & -- & -- \\
\hline Plan 48 & $\$ 1,000$ & $80 \%$ & $\$ 3,000$ & $\$ 25 / \$ 35$ & $14.6 \%$ & $\$ 634$ & -- & -- \\
\hline
\end{tabular}

Notes: This table shows the annual premiums faced for each of the 48 plan combinations for the 23,894 employees with single (emloyee-only) coverage for PY 2010 . The eighth column gives a comparison of the annual premium for that plan combination with the premium for the otherwise equivalent plan with the $\$ 1,000$ deductible. For example, the value $\$ 1,204$ in the first row is calculated by taking the difference between the premium for Plan 1 and for Plan 37. Shaded rows denote plans that are dominated in the sense that the difference in premium between the plan and it's $\$ 1,000$ deductible alternative exceeds the difference in deductibles. In order to fascilitate comparisons based on pre-tax premiums, the last column adjusts the premium differences for the $19 \%$ average marginal tax rate faced by employees based on their income band. Again shaded cells denote dominated plans at each marginal tax rate. 
Table 2

Summary Statistics for Plan Choice and Medical Spending (Single Coverage Only) Data for Plan Year 2010

\begin{tabular}{|c|c|c|c|c|}
\hline Variable & Mean & SD & Variable & Mean \\
\hline Total Benefit Eligible Employees with Plans (in sample) & 51,192 & & Plan Choice by Cost Sharing Feature & \\
\hline \multirow[t]{2}{*}{ Total Employees with Single Coverage Plans (in sample) } & 23,894 & & Deductible Choice & \\
\hline & & & $\$ 350$ & 0.14 \\
\hline Demographics & & & $\$ 500$ & 0.36 \\
\hline Male $($ Yes $=1)$ & 0.29 & -- & $\$ 750$ & 0.13 \\
\hline Approximate Salary (based on salary bands) & $\$ 41,464$ & $\$ 31,158$ & $\$ 1,000$ & 0.37 \\
\hline Approximate Age (based on age ranges) & 39.6 & 13.7 & & \\
\hline Years with firm & 7.8 & 5.1 & Maximum-out-of-pocket after Deductible & \\
\hline Enrolled in company plan prior to 2010 & 0.93 & -- & $\$ 1,500$ & 0.43 \\
\hline \multirow[t]{2}{*}{ Chronic condition $($ Yes $=1)$} & 0.28 & -- & $\$ 2,500$ & 0.30 \\
\hline & & & $\$ 3,000$ & 0.27 \\
\hline \multicolumn{5}{|l|}{ Medical Utilization } \\
\hline Primary care physician visits & 3.1 & 3.8 & Coinsurance Rate after Deductible & \\
\hline Specialits visits & 3.8 & 7.4 & $90 \%$ & 0.47 \\
\hline Preventative Care Visits & 0.43 & 0.57 & $80 \%$ & 0.53 \\
\hline \multirow[t]{2}{*}{ ER visits } & 0.26 & 0.76 & Office Copayment & \\
\hline & & & $\$ 15$ Primary Care/ $\$ 40$ Specialist & 0.30 \\
\hline Medical Care Spending & & & $\$ 25$ Primary Care/ $\$ 35$ Specialist & 0.70 \\
\hline Total medical spending (plan and employee cost-share) & $\$ 3,567$ & $\$ 11,751$ & & \\
\hline Employee out-of-pocket medical spending & $\$ 742$ & $\$ 690$ & Choice into Default Option (Plan 48) & \\
\hline Plan medical spending (non-employee portion) & $\$ 2,826$ & $\$ 11,384$ & Existing Employees & 0.15 \\
\hline Annual premium paid by employee & $\$ 1,205$ & $\$ 454$ & New Hires (No Default) & 0.15 \\
\hline After-tax value of annual premium paid by employee & $\$ 979$ & $\$ 378$ & & \\
\hline Employee total medical spending (premium + out-of-pocket) & $\$ 1,947$ & $\$ 812$ & & \\
\hline Plan spending net of employee premium & $\$ 1,620$ & $\$ 11,348$ & & \\
\hline
\end{tabular}


Table 3

Predictors of Choosing a Dominated Plan and Savings with Counterfactual Alternatives

\begin{tabular}{|c|c|c|c|}
\hline $\begin{array}{l}\text { Dependent variable: } \\
\text { Mean of the dependent variable: }\end{array}$ & $\begin{array}{c}\text { Dominated Plan Choice } \\
0.55 \\
\end{array}$ & $\begin{array}{c}\text { Savings from Switch } \\
\text { to } \$ 1 \mathrm{k} \text { Ded } \\
\$ 221 \\
\end{array}$ & $\begin{array}{c}\text { Savings from Switch to } \\
\text { Plan } 41 \\
\$ 320 \\
\end{array}$ \\
\hline \multicolumn{4}{|l|}{ Salary band ( $\$ 100 \mathrm{k}+$ omitted $)$} \\
\hline$<20 \mathrm{k}$ & $\begin{array}{l}0.24^{* * * *} \\
(0.01)\end{array}$ & $\begin{array}{l}81.59 * * * \\
\quad(5.55)\end{array}$ & $\begin{array}{l}109.62^{* * * *} \\
\quad(7.17)\end{array}$ \\
\hline $20 \mathrm{k}-30 \mathrm{k}$ & $\begin{array}{l}0.28 * * * \\
(0.01)\end{array}$ & $\begin{array}{l}91.64^{* * * *} \\
(4.88)\end{array}$ & $\begin{array}{l}111.36^{* * * *} \\
(6.25)\end{array}$ \\
\hline $30 \mathrm{k}-40 \mathrm{k}$ & $\begin{array}{l}0.30 * * * \\
(0.01)\end{array}$ & $\begin{array}{l}112.03^{* * * *} \\
(5.99)\end{array}$ & $\begin{array}{c}124.41^{* * * *} \\
(7.56)\end{array}$ \\
\hline $40 \mathrm{k}-50 \mathrm{k}$ & $\begin{array}{l}0.07 * * * \\
(0.01)\end{array}$ & $\begin{array}{c}46.88 * * * \\
(6.62)\end{array}$ & $\begin{array}{l}48.16^{* * * *} \\
(8.39)\end{array}$ \\
\hline $50 \mathrm{k}-60 \mathrm{k}$ & $\begin{array}{l}0.03^{*} \\
(0.02)\end{array}$ & $\begin{array}{c}30.97 * * * \\
(8.67)\end{array}$ & $\begin{array}{l}34.99 * * * \\
(11.08)\end{array}$ \\
\hline $60 \mathrm{k}-70 \mathrm{k}$ & $\begin{array}{l}0.06^{* * *} \\
(0.02)\end{array}$ & $\begin{array}{l}35.54^{* * *} \\
(11.42)\end{array}$ & $\begin{array}{c}23.24 \\
(15.12)\end{array}$ \\
\hline $70 \mathrm{k}-80 \mathrm{k}$ & $\begin{array}{c}0.04 \\
(0.03)\end{array}$ & $\begin{array}{c}13.86 \\
(13.13)\end{array}$ & $\begin{array}{c}12.34 \\
(17.89)\end{array}$ \\
\hline $80 \mathrm{k}-90 \mathrm{k}$ & $\begin{array}{l}-0.02 \\
(0.03)\end{array}$ & $\begin{array}{l}-23.42^{* *} \\
(11.56)\end{array}$ & $\begin{array}{l}-18.84 \\
(16.29)\end{array}$ \\
\hline $90 \mathrm{k}-100 \mathrm{k}$ & $\begin{array}{c}0.02 \\
(0.03)\end{array}$ & $\begin{array}{l}-17.69 \\
(12.06)\end{array}$ & $\begin{array}{l}-10.67 \\
(15.63)\end{array}$ \\
\hline \multicolumn{4}{|l|}{ Age band (less than 29 omitted) } \\
\hline $30-39$ & $\begin{array}{c}0.04 * * * \\
(0.01)\end{array}$ & $\begin{array}{c}26.26 * * * \\
(4.63)\end{array}$ & $\begin{array}{c}34.97 * * * \\
(5.73)\end{array}$ \\
\hline $40-49$ & $\begin{array}{c}0.08^{* * * *} \\
(0.01)\end{array}$ & $\begin{array}{c}40.38^{* * * *} \\
(5.11)\end{array}$ & $\begin{array}{c}52.72 * * * \\
(6.52)\end{array}$ \\
\hline $50-59$ & $\begin{array}{c}0.13^{* * *} \\
(0.01)\end{array}$ & $\begin{array}{c}64.61 * * * \\
(5.13)\end{array}$ & $\begin{array}{c}72.93 * * * \\
(6.57)\end{array}$ \\
\hline $60-69$ & $\begin{array}{c}0.18^{* * * *} \\
(0.01)\end{array}$ & $\begin{array}{c}76.12^{* * * *} \\
(7.11)\end{array}$ & $\begin{array}{c}81.34 * * * \\
(9.66)\end{array}$ \\
\hline $70+$ & $\begin{array}{c}0.21^{* * * *} \\
(0.03)\end{array}$ & $\begin{array}{c}110.17^{* * * *} \\
(19.58)\end{array}$ & $\begin{array}{c}142.76^{* * *} \\
(27.04)\end{array}$ \\
\hline Female & $\begin{array}{c}0.06 * * * \\
(0.01)\end{array}$ & $\begin{array}{l}-5.92 \\
(3.73)\end{array}$ & $\begin{array}{l}8.95^{*} \\
(4.62)\end{array}$ \\
\hline Chronic condition & $\begin{array}{c}0.08 * * * \\
(0.01)\end{array}$ & $\begin{array}{c}-32.98 * * * \\
(3.66)\end{array}$ & $\begin{array}{c}-17.64^{* * *} \\
(5.05)\end{array}$ \\
\hline Tenure with company (years) & $\begin{array}{c}0.05^{* * *} \\
(0.01)\end{array}$ & $\begin{array}{c}26.88 * * * \\
(3.58)\end{array}$ & $\begin{array}{c}24.35 * * * \\
(4.76)\end{array}$ \\
\hline New enrolle in company plan & $\begin{array}{c}-0.05 * * * \\
(0.01)\end{array}$ & $\begin{array}{c}-15.54^{* * *} \\
(6.71)\end{array}$ & $\begin{array}{l}-8.75 \\
(8.27) \\
\end{array}$ \\
\hline $\mathrm{N}$ & 23,881 & 23,881 & 23,881 \\
\hline R-squared & 0.10 & 0.04 & 0.03 \\
\hline
\end{tabular}

Note: Heteroskedasticity-robust standard errors in parentheses. Significance at p-value $<0.01$ denoted by $* * *$, p-value $<0.05$ by $* *$, p-value $<0.10$ by $*$. A dominated plan is indicated when the difference in premium the individual paid for the chosen plan versus the equivalent plan with the $\$ 1,000$ deductible (adjusted for tax-deductiblity of premiums using the individual's implied federal marginal tax rate) exceeds the difference between the chosen deductible and $\$ 1,000$. For Column 2 the counterfactual is a switch to the equivalent plan with the $\$ 1,000$ deductible and is $\$ 0$ by construction for those who chose plans with $\$ 1,000$ deductibles. In Column 3 the counterfactual is a switch to plan 41 , which we estimate to be the plan with lowest average employee spending (combining premium and out-of-pocket costs) and is $\$ 0$ by construction for those who chose plan 41 . 
Table 4

Experiment 3: Price Menus by Treatment

\begin{tabular}{lccc}
\hline & \multicolumn{3}{c}{ Annual Premium by Treatment } \\
\cline { 4 - 4 } Option & Less expensive & Baseline & More expensive \\
\hline Plan A - \$350 Deductible & $\$ 1,672$ & $\$ 1,957$ & $\$ 2,242$ \\
Plan B - \$500 Deductible & $\$ 1,269$ & $\$ 1,419$ & $\$ 1,570$ \\
Plan C - \$750 Deductible & $\$ 1,195$ & $\$ 1,321$ & $\$ 1,447$ \\
Plan D - \$1000 Deductible & $\$ 817$ & $\$ 817$ & $\$ 817$ \\
\hline
\end{tabular}

Note: This table shows the premiums for the plan menus used in the three treatments for Experiment 3, described in Section 4.4 . 
Table 5

Understanding the Menu Pricing: Regressions of Premium and Average Cost for Plan Features

\begin{tabular}{|c|c|c|c|c|}
\hline Description: & & Premium Differences & $\begin{array}{c}\text { Average Incremental Cost to Insurer for } \\
\text { Employees Selecting that Coverage }\end{array}$ & $\begin{array}{l}\text { Average Total Cost to Insurer for } \\
\text { Employees Selecting that Coverage }\end{array}$ \\
\hline Dependent Variable: & & Annual Employee Premium & $\begin{array}{l}\text { Average diff in medical spend covered } \\
\text { between chosen plan and mean covered } \\
\text { spend for } 47 \text { alternative plans. }\end{array}$ & $\begin{array}{l}\text { Average medical spend covered by } \\
\text { chosen plan }\end{array}$ \\
\hline Deductible (1,000 omitted) & & & & \\
\hline & 750 & $\begin{array}{l}\$ 528 \\
(19.9)\end{array}$ & $\begin{array}{l}\$ 84 \\
(15.5)\end{array}$ & $\begin{array}{l}\$ 627 \\
(457)\end{array}$ \\
\hline & 500 & $\begin{array}{l}\$ 625 \\
(19.9)\end{array}$ & $\begin{array}{l}\$ 230 \\
(15.5)\end{array}$ & $\begin{array}{r}\$ 1,211 \\
(457)\end{array}$ \\
\hline & 350 & $\begin{array}{r}\$ 1,156 \\
(19.9)\end{array}$ & $\begin{array}{l}\$ 339 \\
(15.5)\end{array}$ & $\begin{array}{r}\$ 2,304 \\
(457)\end{array}$ \\
\hline MOOP (3,000 omitted) & & & & \\
\hline & 2,500 & $\begin{array}{l}\$ 108 \\
(17.2)\end{array}$ & $\begin{array}{l}\$ 13 \\
(13.4)\end{array}$ & $\begin{array}{l}\$ 204 \\
(396)\end{array}$ \\
\hline & 1,500 & $\begin{array}{l}\$ 259 \\
(17.2)\end{array}$ & $\begin{array}{l}\$ 78 \\
(13.4)\end{array}$ & $\begin{array}{l}\$ 610 \\
(396)\end{array}$ \\
\hline Coinsurance ( $80 \%$ omitted) & & & & \\
\hline & $90 \%$ & $\begin{array}{l}\$ 93 \\
(14.0)\end{array}$ & $\begin{array}{l}\$ 154 \\
(11.0)\end{array}$ & $\begin{array}{r}\$ 1,322 \\
(323)\end{array}$ \\
\hline Copay (25/40 omitted) & & & & \\
\hline & $15 / 35$ & $\begin{array}{l}\$ 76 \\
(14.0)\end{array}$ & $\begin{array}{c}\$ 0 \\
(11.0)\end{array}$ & $\begin{array}{l}\$ 354 \\
(323)\end{array}$ \\
\hline Constant & & $\begin{array}{c}\$ 522 \\
(19.86)\end{array}$ & $\begin{array}{r}-\$ 243 \\
(15.5) \\
\end{array}$ & $\begin{array}{l}\$ 731 \\
(457)\end{array}$ \\
\hline $\mathrm{N}$ & & 48 & 48 & 48 \\
\hline Adjusted R-squared & & 0.99 & 0.94 & 0.47 \\
\hline
\end{tabular}




\section{APPENDIX}

Appendix Figure A - Experiment Overview

Three hypothetical plan choice experiments test potential explanations for poor choice quality

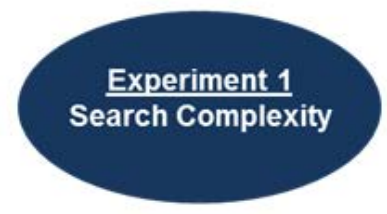

Do search frictions and menu complexity lead to poor choice quality?

- $\mathrm{N}=2,317$ (completed) from Qualtrics • survey panel

- Sample: US adults with health insurance

- Outcome: Hypothetical choice from plan menu varying in size and structure

- Interventions $(2 \times 2 \times 2)$ :

- Sequential versus comparison plan choice

- 1 (Deductible) versus 2

(Deductible and MOOP) attributes

- Monthly versus annual premium display

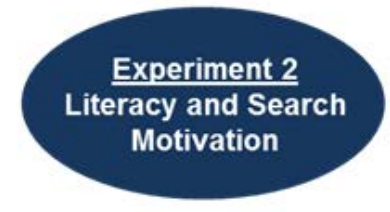

Do deficits in health plan literacy and search motivation lead to poor choice quality?

$\mathbf{N}=\mathbf{6 2 4}$ (completed) from Qualtrics survey panel

- Sample: US adults with health insurance

Assessments: Literacy and motivation - Outcome: Hypothetical choice from (comparison) plan menu with annualized deductible (with 1 and 2 attributes)

- Interventions $(3 \times 1)$ :

- Control

- Motivation: Communicates

financial consequences of choice

- Literacy: Offers scenario based instruction for efficient choice

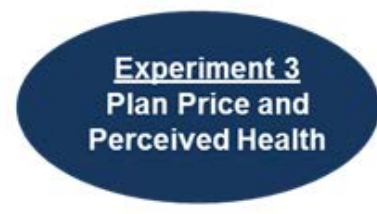

Do plan choices reflect considerations of perceived health risk and plan prices?

- $\mathbf{N}=\mathbf{7 3 4}$ (completed) from Amazon Mechanical Turk

- Sample: US adults

- Assessments: Perceived health risk

- Outcome: Hypothetical choice from (comparison) plan menu with annualized deductible and varying prices (1 attribute)

- Interventions (3 $\times 1)$ :

- Control

- More Expensive: Low-deductible plans $125 \%$ more costly than $\$ 1,000$ deductible plan relative to control - Less Expensive: Low-deductible plans $75 \%$ less costly than $\$ 1,000$ deductible plan relative to control 
Appendix Figure B - Experiment 1 (Search Complexity)

Select plan menus faced by subjects in comparison choice conditions

(menus vary by number of attribute combinations and time-horizon of premium display)

The following table tells you how much you would pay in premium for the deductible you select.

\begin{tabular}{|cccc|}
\hline \multicolumn{4}{|c|}{ TABLE OF MONTHLY PREMIUMS FOR HEALTH PLAN OPTIONS } \\
\hline \multirow{4}{*}{ DEDUCTIBLE } & $\$ 750$ & $\$ 1000$ \\
\hline$\$ 350$ & $\$ 500$ & $\$ 110 /$ month & $\$ 68 /$ month \\
\hline$\$ 163 /$ month & $\$ 118 /$ month & $\$$
\end{tabular}

The following table tells you how much you would pay in premium for the deductible and out-of-pocket maximum you select.

\begin{tabular}{lccc}
\hline \multicolumn{4}{c}{ TABLE OF MONTHLY PREMIUMS FOR HEALTH PLAN OPTIONS } \\
\hline DEDUCTIBLE & \multicolumn{3}{c|}{ OUT-OF-POCKET MAXIMUM } \\
\hline$\$ 350$ & $\$ 1500$ & $\$ 2500$ & $\$ 3000$ \\
$\$ 500$ & $\$ 163 /$ month & $\$ 151 /$ month & $\$ 134 /$ month \\
$\$ 750$ & $\$ 118 /$ month & $\$ 104 /$ month & $\$ 93 /$ month \\
$\$ 1000$ & $\$ 110 /$ month & $\$ 97 /$ month & $\$ 86 /$ month \\
\hline
\end{tabular}

The following table tells you how much you would pay in premium for the deductible and out-of-pocket maximum you select.

\begin{tabular}{lccc}
\hline \multicolumn{4}{c}{ TABLE OF YEARLY PREMIUMS FOR HEALTH PLAN OPTIONS } \\
\hline \multicolumn{4}{c|}{ OUT-OF-POCKET MAXIMUM } \\
DEDUCTIBLE & $\$ 1500$ & $\$ 2500$ & $\$ 3000$ \\
\hline$\$ 350$ & $\$ 1957 /$ year & $\$ 1808 /$ year & $\$ 1605 /$ year \\
$\$ 500$ & $\$ 1419 /$ year & $\$ 1252 /$ year & $\$ 1114 /$ year \\
$\$ 750$ & $\$ 1321 /$ year & $\$ 1168 /$ year & $\$ 1038 /$ year \\
$\$ 1000$ & $\$ 817 /$ year & $\$ 662 /$ year & $\$ 634 /$ year \\
\hline
\end{tabular}

- Comparison Choice

- Single Attribute

- Monthly Premiums

- Comparison Choice

- Two Attributes

- Monthly Premiums

- Comparison Choice

- Two Attributes

- Annual Premiums 


\section{Appendix Figure C - Experiment 2 (Health Literacy)}

Select modules from health literacy intervention completed by subjects prior to plan choice

In the final part of the survey, we will ask you to choose a health plan from a menu of

However, betore you choose, we'd like to spend a few minutes and walk you through a couple mustrative scenarios. For these scenanios imagine that you are only responsible for your own

First, in is helpful to define two terms

A plan premium is the amount that must be paid for a health plan (usually monthis.

A plan deductible is the annual amount that must be paid out-of-pocket for medical care

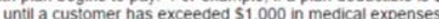

Yes, you are correct:

No matter what, Bill would end up paying less with Plan Green.

Why? Note that plans with lower deductibles (here, Plan Blue) cost more in annual premium

If Bill does not use any medical care, he will definitely pay more with the low deductible plan If Bill does use care, the low deductible plan may save him money by reducing his out-ofpocket spending but will only be cheaper overall if these savings are larger than the additionat pocket spending
plan premium.

In this example, if Bill chooses Plan Blue, he has to pay an additional $\$ 800$ in premium can only save him a maximum of $\$ 400$ in out-ot-pocket spending ( $\$ 800-\$ 400)$.

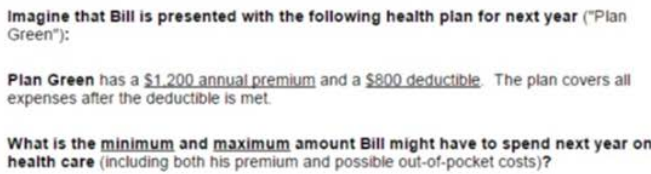

Imagine that Bill is presented with the following health plan for next year ("Plan Green"

Plan Green has a $\$ 1.200$ annual premium and a $\$ 800$ deductible. The plan covers all expenses after the deductible is met.

What is the minimum and maximum amount Bill might have to spend next year on health care (including both his premium and possible out-of-pocket costs)?

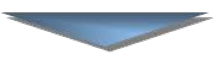

Now imagine that Bill has the option of choosing between the same Plan Green or a new Plan Blue.

The plans provide access to the same doctors and quality of service, but the plans have the following features: Plan Green has a $\$ 1200$ annual premium and a $\$ 800$ deductible. The plan covers all
expenses after the deductible is met

Plan Blue has a $\$ 2.000$ annual premium and a $\$ 400$ deductible. The plan covers all

For each of the following scenarios, which plan will be cheaper for Bill? 